\title{
Chemistry, transport and dry deposition of trace gases in the boundary layer over the tropical Atlantic Ocean and the Guyanas during the GABRIEL field campaign
}

\author{
A. Stickler ${ }^{1, * *}$, H. Fischer ${ }^{1}$, H. Bozem ${ }^{1}$, C. Gurk ${ }^{1}$, C. Schiller ${ }^{2}$, M. Martinez-Harder ${ }^{1}$, D. Kubistin ${ }^{1}$, H. Harder ${ }^{1}$, \\ J. Williams ${ }^{1}$, G. Eerdekens ${ }^{1}$, N. Yassaa ${ }^{1}$, L. Ganzeveld ${ }^{1, *}$, R. Sander ${ }^{1}$, and J. Lelieveld ${ }^{1}$ \\ ${ }^{1}$ Department of Atmospheric Chemistry, Max Planck Institute for Chemistry, Mainz, Germany \\ ${ }^{2}$ Department of Chemistry, York University, Toronto, Canada \\ *now at: Department of Earth System Science, University Wageningen, The Netherlands \\ *** now at: Institute for Atmospheric and Climate Science, ETH Zürich, Switzerland
}

Received: 6 February 2007 - Published in Atmos. Chem. Phys. Discuss.: 5 April 2007

Revised: 17 July 2007 - Accepted: 19 July 2007 - Published: 25 July 2007

\begin{abstract}
We present a comparison of different Lagrangian and chemical box model calculations with measurement data obtained during the GABRIEL campaign over the tropical Atlantic Ocean and the Amazon rainforest in the Guyanas, October 2005. Lagrangian modelling of boundary layer (BL) air constrained by measurements is used to derive a horizontal gradient $\left(\approx 5.6 \mathrm{pmol} / \mathrm{mol} \mathrm{km}^{-1}\right)$ of $\mathrm{CO}$ from the ocean to the rainforest (east to west). This is significantly smaller than that derived from the measurements (16$48 \mathrm{pmol} / \mathrm{mol} \mathrm{km}^{-1}$ ), indicating that photochemical production from organic precursors alone cannot explain the observed strong gradient. It appears that $\mathrm{HCHO}$ is overestimated by the Lagrangian and chemical box models, which include dry deposition but not exchange with the free troposphere (FT). The relatively short lifetime of HCHO implies substantial BL-FT exchange. The mixing-in of FT air affected by African and South American biomass burning at an estimated rate of $0.12 \mathrm{~h}^{-1}$ increases the $\mathrm{CO}$ and decreases the HCHO mixing ratios, improving agreement with measurements. A mean deposition velocity of $1.35 \mathrm{~cm} / \mathrm{s}$ for $\mathrm{H}_{2} \mathrm{O}_{2}$ over the ocean as well as over the rainforest is deduced assuming BL-FT exchange adequate to the results for $\mathrm{CO}$. The measured increase of the organic peroxides from the ocean to the rainforest $\left(\approx 0.66 \mathrm{nmol} / \mathrm{mol} \mathrm{d}^{-1}\right)$ is significantly overestimated by the Lagrangian model, even when using high values for the deposition velocity and the entrainment rate. Our results point at either heterogeneous loss of organic peroxides and/or their radical precursors, underestimated photodissociation or missing reaction paths of peroxy radicals not forming peroxides in isoprene chemistry. We calculate a mean integrated daytime net ozone production (NOP) in the
\end{abstract}

Correspondence to: A. Stickler

(alexander.stickler@env.ethz.ch)
BL of $(0.2 \pm 5.9) \mathrm{nmol} / \mathrm{mol}$ (ocean) and $(2.4 \pm 2.1) \mathrm{nmol} / \mathrm{mol}$ (rainforest). The NOP strongly correlates with NO and has a positive tendency in the boundary layer over the rainforest.

\section{Introduction}

Despite the relatively small coverage of less than about $8 \%$ of the global land surface by tropical rainforests (areas classified as evergreen broadleef forests in Loveland et al., 2000), these regions are known to be a major global source of reactive trace gases, primarily through vegetation emissions, partly because of the diverse and opulent flora and also because biogenic emissions are generally stimulated by high temperatures and/or irradiation intensity (see e.g. Kesselmeier and Staudt, 1999; Padhy and Varshney, 2005; Carvalho et al., 2005). These trace gases have a strong impact on the atmospheric oxidation capacity (e.g. Fehsenfeld et al., 1992). The Amazon basin including the Guyanas comprises the largest rainforest ecosystem worldwide. Although the region is perturbed by deforestation and burning, especially the Guyanas offer opportunities for atmospheric research in a relatively pristine environment. The Guyanas do not have a pronounced biomass burning season, and fresh $(<2 \mathrm{~d})$ air pollution is rarely encountered. However, longrange transport of biomass burning pollution predominantly from Africa but also from South America, as well as of anthropogenic pollution from the Northern Hemisphere into the FT above the Guyanas has been reported to occur frequently (Peters et al., 2004). The region of the Guyanas (see Fig. 1) is characterised by low-level north-easterly and eastsoutheasterly trade winds, respectively, during both dry seasons from February to March and from August to November.

Published by Copernicus Publications on behalf of the European Geosciences Union. 


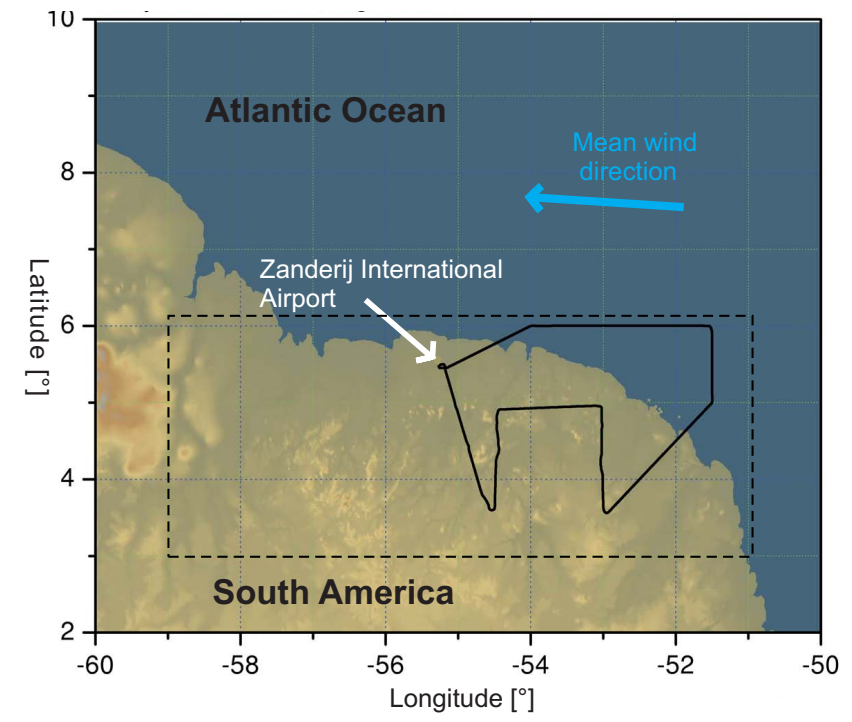

Fig. 1. Operations area (black dashed rectangle) of the Learjet 35A during the GABRIEL campaign. The flight track of flight G04 is indicated by a black line. The north-south flight legs are (from east to west) the segments G04a, G04b and G04c. The map shows part of the Guyana Highlands (in the west and south) and the coastal plains of Guyana, Suriname and French Guyana. The track of flight G07 is close to that of G04.

Therefore strong horizontal trace gas gradients can develop due to the build-up of biogenic emissions and oxidation products from the forest. To assess the atmospheric fate of a trace gas, the ratios of its various chemical and physical lifetimes can be used, defined as the concentration divided by the respective loss rate (see e.g. Finlayson-Pitts and Pitts, 2000).

In this context, chemical box models as well as 1-D models have proven to be successful numerical tools to evaluate the relative importance of different chemical or physical processes influencing trace gas mixing ratios (e.g. Ganzeveld et al., 2006a,b; Stickler et al., 2006). However, when comparing box model results with measurement data it is important to ensure that some basic implicit assumptions are fulfilled: a) the air has to be well mixed, and b) the amount of mixingin of air with known properties from the surrounding area as well as possible physical sinks of trace gases like deposition have to be known. The simplest case is one without exchange and deposition, which is assumed to be true e.g. in free tropospheric "steady state" calculations of radical species and sometimes also for longer-lived species. In the planetary boundary layer (BL) on the other hand, dry deposition cannot be neglected for many trace gases (e.g. $\mathrm{HNO}_{3}, \mathrm{HCHO}$ and peroxides) if there exists a thermally unstable stratification or wind shear leading to turbulent transport towards the surface at a timescale shorter than their chemical lifetime. Conversely, these turbulent motions are a necessary prerequisite for the required homogeneity inside the studied "box" of air. In the case of relatively undisturbed conditions, the tropical
BL can be expected to be best mixed from the late morning to the early evening. Its well-mixed state is characterised by a nearly constant potential temperature and wind speed profile (e.g. Holton, 1992). Under these circumstances, if only entrainment from the FT or deposition is unknown, it can in principle be estimated from a numerical simulation with the other parameters fixed to measured values.

Entrainment of air from the FT into the BL, defined as the exchange rate of BL air by FT air, is determined by two processes: a) small-scale turbulent as well as larger-scale convective mixing-in of FT air into the BL and b) changing height of the well mixed part of the BL (e.g. Seinfeld and Pandis, 1998). The first two processes, like the dry deposition, depend on the vertical stability of the air mass governed by the vertical temperature gradient and the vertical wind shear. Regarding the second process, when the BL height increases, mass conservation requires a mass flux from above, while a descending mixed layer height does not directly change the mixing ratios of trace gases within the BL.

Dry deposition on the other hand is determined, besides the BL vertical stability, by the chemical properties of the species and finally by the nature of the surface itself. For gases, chemical reactivity and solubility affect the uptake at the surface. The dry deposition velocity $v_{d}$ is a generally altitude dependent measure for dry deposition and, by multiplying with the concentration of the species, gives the deposition flux. As a consequence, the complex deposition processes can be condensed into a single parameter, suitable e.g. for a box model. In explicit calculations, like the ones made with the 1-D Single Column Model (SCM) whose output has also been used in this study, dry deposition is represented explicitly by a) the transport to the surface layer, $b$ ) molecular transport through this layer to the surface and c) uptake at the surface.

Section 2 presents a brief mission description and summarises the measurements carried out to obtain the data set used in this study. Section 3 describes the box model used to analyse the data and the boundary conditions for the Lagrangian and "steady state" mode as derived from the measurements and a 1-D SCM. Section 4 presents results of different model runs, compares these with the trace gas measurements and interprets the data set. The influences of chemistry, transport and dry deposition for $\mathrm{CO}, \mathrm{HCHO}$, $\mathrm{H}_{2} \mathrm{O}_{2}$ and organic peroxide are investigated for typical "low $\mathrm{NO}_{\mathrm{x}}$ " (approx. $<20-25 \mathrm{pmol} / \mathrm{mol}$, no direct influence by biomass burning) boundary layer conditions over the tropical Atlantic Ocean and the rainforest of the Guyanas during the long dry season.

\section{Mission description}

The GABRIEL campaign in October 2005 was a followup of the 1998 LBA-CLAIRE experiment, investigating the 
Table 1. Synopsis of flights performed during the GABRIEL campaign. Flight Pattern: G=General Flight Pattern (ascent up to an altitude of about 6.5 to $8 \mathrm{~km}$ a.s.1., descent into the BL $(\approx 300-500 \mathrm{~m}$ a.s.1.), alternating legs in the BL and the FT up to an altitude of about 3 to $3.5 \mathrm{~km}$, and ascent to relatively higher levels above 5 to $6 \mathrm{~km}$ before landing); $3 \mathrm{~A}=3 \mathrm{rd}$ ascent in the middle of the flight; $\mathrm{C}=\mathrm{only} 1 \mathrm{transit}$ from $\mathrm{BL}$ to FT in the middle of the flight, high ascent up to $11 \mathrm{~km}$ a.s.l.; MT=longer stay in middle troposphere, only 1 short dive into BL.

\begin{tabular}{llllll}
\hline Flight & Date & Time of Day & Subregion & Vertical Flight Pattern & Objective \\
\hline G01 & 3 Oct 2005 & Afternoon & East & G & E-W transect \\
G02 & 5 Oct 2005 & Noon & East & G & E-W transect \\
G03 & 6 Oct 2005 & Afternoon & East & G & E-W transect \\
G04 & 7 Oct 2005 & Noon & East & G + 3A & N-S transects at different longitudes \\
G05 & 8 Oct 2005 & Noon & Centre & G & N-S transects at different longitudes \\
G06 & 10 Oct 2005 & Afternoon & East & G & E-W transect \\
G07 & 11 Oct 2005 & Morning & East & G + 3A & N-S transects at different longitudes \\
G08 & 12 Oct 2005 & Afternoon & Centre & C & N-S transects, convective outflow, coastal emissions \\
G09 & 13 Oct 2005 & Afternoon & West & MT & N-S transects at different longitudes \\
G10 & 15 Oct 2005 & Morning & Centre & G & N-S transects at different longitudes \\
\hline
\end{tabular}

Table 2. Synopsis of measured species during the GABRIEL campaign.

\begin{tabular}{|c|c|c|c|c|c|}
\hline Species & Measurement technique & $\mathrm{DL}[\mathrm{nmol} / \mathrm{mol}]$ & Precision & Accuracy & Systematic error [\%] \\
\hline $\mathrm{CO}$ & TDLAS & 0.2 & & $2.5 \%$ & \\
\hline $\mathrm{HCHO}$ & TDLAS & 0.25 & $25 \%$ & $26.9 \%$ & \\
\hline $\mathrm{H}_{2} \mathrm{O}_{2}$ & derivatisation + fluorimetry & 0.029 & $9.7 \%$ & $14.8 \%$ & $<+25-30$ \\
\hline $\mathrm{ROOH}$ & derivatisation + fluorimetry & $<0.029$ & $<9.7 \%$ & $25.9 \%$ & \\
\hline $\mathrm{OH}$ & LIF & 0.00002 & $0.000035 \mathrm{pmol} / \mathrm{mol}$ & $40 \%(56 \%)$ & \\
\hline $\mathrm{HO}_{2}$ & LIF & 0.00007 & $0.0005 \mathrm{pmol} / \mathrm{mol}$ & $60 \%$ & \\
\hline $\mathrm{NO}$ & chemiluminescence & 0.005 & & $12 \%$ & \\
\hline $\mathrm{O}_{3}$ & chemiluminescence & 2 & & $2 \%$ & \\
\hline$J\left(\mathrm{NO}_{2}\right)$ & filter radiometer & & $1 \%$ & $10 \%$ & \\
\hline $\mathrm{CH}_{3} \mathrm{OH}$ & PTR-MS & 0.269 & $39 \%$ & 5-10\% (excl. prec.) & \\
\hline $\mathrm{CH}_{3} \mathrm{CN}$ & PTR-MS & 0.068 & $20 \%$ & 5-10\% (excl. prec.) & \\
\hline $\mathrm{CH}_{3} \mathrm{C}(\mathrm{O}) \mathrm{CH}_{3}$ & PTR-MS & 0.094 & $17 \%$ & 5-10\% (excl. prec.) & \\
\hline isoprene & PTR-MS & 0.099 & $7 \%$ & 5-10\% (excl. prec.) & \\
\hline MVK & PTR-MS & 0.093 & $12 \%$ & 5-10\% (excl. prec.) & \\
\hline $\mathrm{H}_{2} \mathrm{O}$ & LI-COR & 200000 & & $5 \%$ & \\
\hline $\mathrm{CO}_{2}$ & LI-COR & & & $0.3 \mu \mathrm{mol} / \mathrm{mol}$ & \\
\hline
\end{tabular}

biosphere-atmosphere exchange of natural trace gases and quantifying chemical processes in the atmosphere above the tropical forest. Additionally, aerosol properties over the rain forest and long-range transport of biomass smoke and mineral dust were studied. The payload of the aircraft, a Learjet 35A of the Gesellschaft für Flugzieldarstellung (GFD, Hohn, Germany) based at Johann A. Pengel International Airport at Zanderij (see Fig. 1), was extended compared to LBACLAIRE, e.g. with additional in situ peroxide $\left(\mathrm{H}_{2} \mathrm{O}_{2}\right.$ and organic peroxide), $\mathrm{HCHO}$, and the first reported $\mathrm{HO}_{\mathrm{x}}$ measurements over the tropical rainforest. The extended payload was especially designed to allow for more detailed and better constrained studies particularly of the chemical processes connected to the oxidative capacity of the tropical troposphere. Flights were conducted in a region from $3^{\circ} \mathrm{N} 59^{\circ} \mathrm{W}$ to $6^{\circ} \mathrm{N} 51^{\circ} \mathrm{W}$ over the tropical Atlantic Ocean, mainly northeast of French Guyana, as well as over continental regions of Guyana, Suriname and French Guyana, all mostly covered by tropical rainforest. The flight patterns were designed to allow for sampling both in the BL and in the FT. A summary of the flights can be found in Table 1. A synopsis of the measurements including measured parameters, precisions and accuracies is listed in Table $2^{1}$.

\footnotetext{
${ }^{1} \mathrm{~A}$ detailed discussion of the measurements can be found in a joint overview paper by Lelieveld et al. and Martinez et al., Atmos. Chem. Phys. Discuss., in preparation, 2007.
} 
Table 3. Mixing ratios of the species kept fixed in the box model runs. Data from the ESRL Global Monitoring Division comprise measurements from the "Atlantic Ocean Cruise" at $5^{\circ} \mathrm{N}$ (autumn 2005), see http://www.cmdl.noaa.gov and http://www.cmdl.noaa.gov/ccgg/iadv/). For the LBA-CLAIRE98 measurements of IMAU, median values within the altitude range $0-1 \mathrm{~km}$ a.s.l. were calculated.

\begin{tabular}{lll}
\hline Species & Mixing ratio & Reference \\
\hline $\mathrm{CO}_{2}$ & $377 \mu \mathrm{mol} / \mathrm{mol}$ & NOAA CMDL Global Trends, ESRL Global Monitoring Division \\
$\mathrm{CH}_{4}$ & $1760 \mathrm{nmol} / \mathrm{mol}$ & NOAA CMDL Global Trends, ESRL Global Monitoring Division \\
$\mathrm{H}_{2}$ & $563 \mathrm{nmol} / \mathrm{mol}$ & Schmidt (1974, 1978) \\
$\mathrm{C}_{2} \mathrm{H}_{6}$ & $794 \mathrm{pmol} / \mathrm{mol}$ & LBA-CLAIRE98, IMAU (Univ. Utrecht, The Netherlands) \\
$\mathrm{C}_{3} \mathrm{H}_{8}$ & $83 \mathrm{pmol} / \mathrm{mol}$ & LBA-CLAIRE98, IMAU (Univ. Utrecht, The Netherlands) \\
$n$ n-butane + iso-butane & $28 \mathrm{pmol} / \mathrm{mol}$ & LBA-CLAIRE98, IMAU (Univ. Utrecht, The Netherlands) \\
$\mathrm{C}_{3} \mathrm{H}_{6}$ & $84 \mathrm{pmol} / \mathrm{mol}$ & LBA-CLAIRE98, IMAU (Univ. Utrecht, The Netherlands) \\
$\mathrm{C}_{2} \mathrm{H}_{4}$ & $650 \mathrm{pmol} / \mathrm{mol}$ & $305 \mathrm{~m}$ a.s.l., GTE ABLE 2A, Manaus (Brazil) (Zimmerman et al., 1988) \\
\hline
\end{tabular}

\section{Box model}

\subsection{Model description}

The box model is based on a version previously used to determine the influence of summertime deep convection on the formaldehyde budget over Europe by Stickler et al. (2006) and Stickler (2006). It contains the MECCA v0.1p chemical mechanism (Sander et al., 2005) with a maximum number of 116 species and 295 reactions in the gas phase. 110 gas phase reactions and 34 photolysis reactions are explicitly simulated with up-to-date kinetic data in the "troposphere, gas phase, no sulfur, no halogens" mode. The list of reactions can be found in the electronic supplement of Sander et al. (2005), whereby the mode mentioned corresponds to all reactions with the labels $\operatorname{Tr}$ and $\mathrm{G}$ except the ones also labeled with $\mathrm{Cl}, \mathrm{F}, \mathrm{Br}$, I or S. Heterogeneous and aqueous phase reactions are not included in the present study.

$J$-values were calculated with a radiative transfer model (TUV v4.1, Tropospheric Ultraviolet-Visible Model, Madronich and Flocke, 1998) which includes a parameterisation for aerosol (total aerosol optical density $O D=0.34$ at $\lambda=340 \mathrm{~nm}$ ). The total ozone column used to scale the ozone profile in the radiative transfer model was fixed to $7.1285 \times 10^{18} \mathrm{~cm}^{-2}$ (三265 DU). Otherwise the TUV settings have been left unchanged compared to Stickler et al. (2006). From measured and modelled $J\left(\mathrm{NO}_{2}\right)$ a cloud correction factor (CCF), to compensate for cloud and aerosol effects, could be calculated, which was then applied to the model results. Here we use different model runs to calculate $\mathrm{CO}, \mathrm{HCHO}$, $\mathrm{H}_{2} \mathrm{O}_{2}$ and organic peroxide mixing ratios. The remainder of the measured species is constrained by the measurements as described below. All other species are held constant (see next section).

\subsection{Specific settings in the Lagrangian mode}

The Lagrangian approach can be thought of as a box, not necessarily closed with respect to mass, being traced along a trajectory and applying constraints based on measurements (e.g. prescribed trace gas mixing ratios and fluxes, radiation etc.). For the Lagrangian calculation of $\mathrm{CO}, \mathrm{HCHO}$ and peroxide mixing ratios, the mixing ratios of the long-lived and medium-lived species $\mathrm{CO}_{2}, \mathrm{CH}_{4}, \mathrm{H}_{2}$ as well as alkanes and alkenes were set to fixed values. Since alkanes and alkenes except isoprene were not measured the respective mixing ratios were estimated based on GC-FID measurement results of the Institute of Marine and Atmospheric Research (IMAU) at the University of Utrecht (The Netherlands) obtained during the LBA-CLAIRE98 campaign for the short dry season and in the same region. For $\mathrm{C}_{2} \mathrm{H}_{4}$ there was no measurement data available for either campaign, so that $\mathrm{BL}$ data obtained during GTE ABLE 2A near Manaus during the dry season (northern hemispheric summer) was assumed to be representative. A summary of all fixed species can be found in Table 3. All values listed there were set to be constant since the sensitivity of the species examined in the present study towards alkanes and alkenes was found to be minor or intermediate (see e.g. Stickler et al., 2006, and Appendix B). The above mentioned settings were also used for the "steady state" mode of the box model described in Sect. 3.3.

For $\mathrm{CO}, \mathrm{HCHO}, \mathrm{H}_{2} \mathrm{O}_{2}$, organic peroxide, $\mathrm{NO}$, acetone, methanol, isoprene, $\mathrm{MVK}, \mathrm{H}_{2} \mathrm{O}, \mathrm{O}_{3}, \mathrm{OH}$ and $\mathrm{HO}_{2}$ longitudinal gradients of the median mixing ratios with a resolution of $1^{\circ}$ were derived for the whole data set in the altitude range $0-1 \mathrm{~km}$ a.s.l. (see e.g. Figs. 2 to 5 ). In the case of $\mathrm{HCHO}$, the peroxides, $\mathrm{NO}$ and $\mathrm{HO}_{\mathrm{x}}$ diurnal cycles in time steps of $5000 \mathrm{~s}$, beginning at $\approx 06: 55 \mathrm{LT}$ and ending at 16:40 LT, were additionally inferred from the measurements. With the exception of $\mathrm{NO}, \mathrm{OH}$ and $\mathrm{HO}_{2}$, these diurnal cycles were then "closed" by linearly interpolating the mixing ratios through the nighttime. These three compounds were set to 0 before sunrise (06:00 LT) and after sunset (18:00 LT) to reflect their low nighttime concentration. Diurnal cycles of isoprene, MVK and the photolysis rates were constructed by assuming a proportionality to the sine of the solar elevation angle. The median mixing ratios in the easternmost longitude 


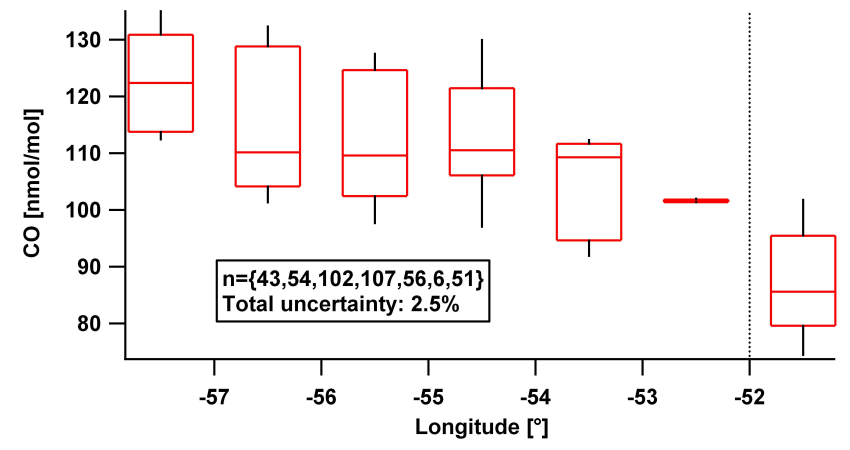

Fig. 2. Longitude profile of the $\mathrm{CO}$ median mixing ratio in the altitude range $0-1 \mathrm{~km}$ a.s.l.; red bar denotes the median; the lower and upper boundary of the red box mark the $25 \%$ and $75 \%$ percentiles, the bottom and top whisker the $10 \%$ and $90 \%$ percentiles. The dotted black line separates the longitudinal range dominated by BL measurements over the ocean in the east from BL measurements taken predominantly over land in the west.

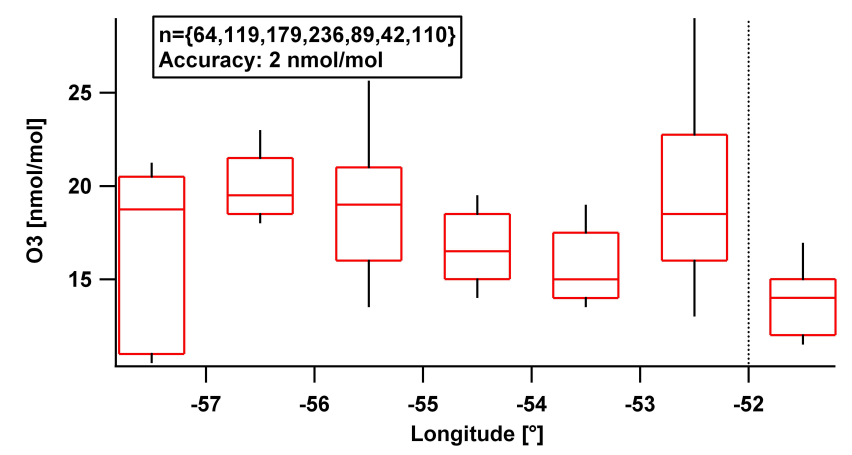

Fig. 3. Longitude profile of the $\mathrm{O}_{3}$ median mixing ratio in the altitude range $0-1 \mathrm{~km}$ a.s.1.; as Fig. 2.

bin centred at $51.5^{\circ} \mathrm{W}$ were defined as start values $(t=0)$ for the Lagrangian mode. In the case of species subject to diurnal cycles, the solar dependency was combined with the longitude gradient. Starting with the median mixing ratio of the easternmost bin, the air parcel was assumed to travel westward with the measured mean velocity of $5.6 \mathrm{~m} / \mathrm{s}$ at 0 $1 \mathrm{~km}$ a.s.l. (measured mean wind direction: $\left.(95 \pm 48)^{\circ}\right)$. Thus it takes $330 \mathrm{~min}$ to cross $1^{\circ}$ longitude, approximately equivalent to $60 \mathrm{~nm} \approx 111 \mathrm{~km}$, close to the equator, and a distance of $\approx 4.36^{\circ}$ or $484 \mathrm{~km}$ is covered in $24 \mathrm{~h}$. From the starting value of the mixing ratio and the local time, the maximum of the diurnal cycle was calculated. The latter was then updated along the trajectory by adding the integrated horizontal gradient of the species over the covered distance. Whenever this combination led to negative values, mainly due to either a strong diurnal cycle $\left(\mathrm{HCHO}, \mathrm{HO}_{2}\right)$ or a negative longitude gradient $\left(\mathrm{H}_{2} \mathrm{O}_{2}\right)$, the resulting mixing ratios were set to zero. For the long-lived trace gases without a diurnal cycle the integrated horizontal gradient was directly added to the starting value of the mixing ratio. The model run was stopped after having traversed a distance of $6^{\circ}$ in $33 \mathrm{~h}$.

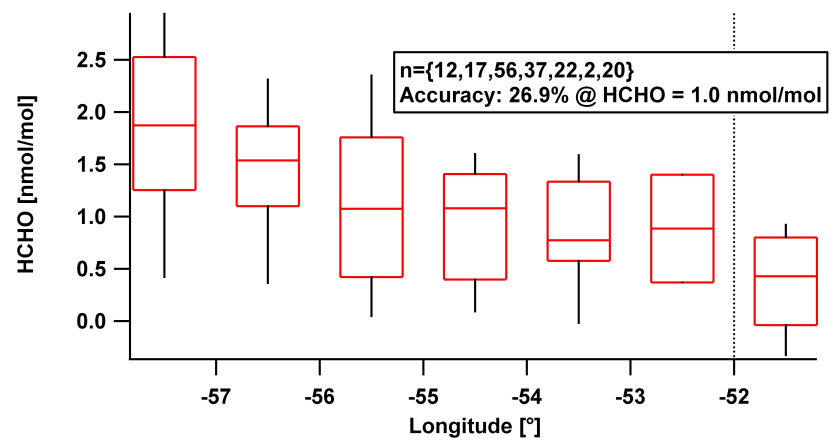

Fig. 4. Longitude profile of the HCHO median mixing ratio in the altitude range $0-1 \mathrm{~km}$ a.s.1.; as Fig. 2.

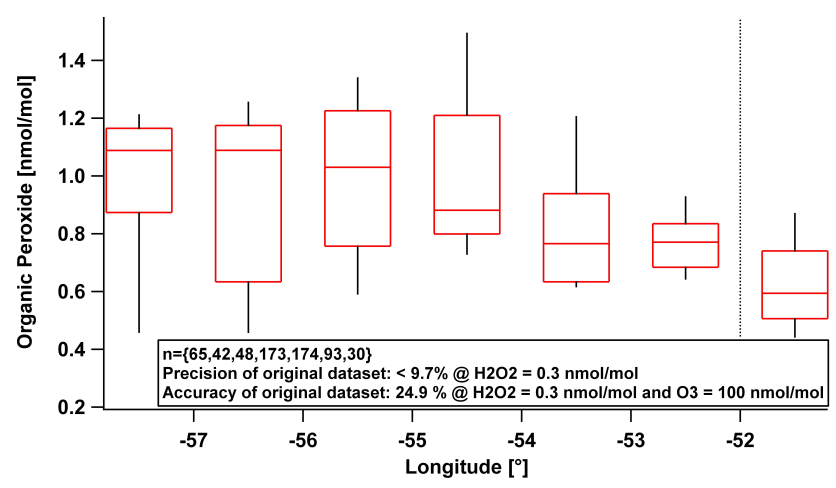

Fig. 5. Longitude profile of the total organic peroxide median mixing ratio in the altitude range $0-1 \mathrm{~km}$ a.s.1.; as Fig. 2.

At the starting point in the centre of the ocean bin $\left(51.5^{\circ} \mathrm{W}\right)$ the organic peroxides were assumed to consist solely of $\mathrm{CH}_{3} \mathrm{OOH}$. At the centre points of the bins located further westward over the continent, $60 \%$ of the organic peroxide was assumed to be methyl hydroperoxide while the rest was equally distributed over peroxides formed during isoprene oxidation (lumped species ISOOH in MECCA v0.1p) and peroxides formed during MVK oxidation (lumped species $\mathrm{MVKOOH}$ ). This ensures that the diurnal mean of the $\mathrm{CH}_{3} \mathrm{OOH}$ mixing ratio stays roughly constant along the trajectory. In the boundary layer above the rainforest isoprene and its oxidation product MVK are expected to be the major contributors to $\mathrm{RO}_{2}$ and organic peroxide formation due to their high reactivity and abundance. Sensitivity runs were done with altered partitioning of these 3 peroxides. The mixing ratios of all other organic peroxides in the chemical mechanism were consistently set to zero.

Organic nitrates, nitrooxy acetaldehyde (NACA, formed in the model reaction of nitrates from isoprene with $\mathrm{OH}$ ), $\mathrm{HNO}_{3}$ and $\mathrm{HNO}_{4}$ were set to zero in the reference run, too, considering their negligible influence on HCHO (the latter being an ideal indicator for photochemical degradation of VOCs). $\mathrm{HNO}_{3}$ is only marginally relevant as a source of $\mathrm{NO}_{3}$ in the model. Nevertheless, several sensitivity runs, including 
one with freely calculated $\mathrm{NO}_{\mathrm{z}} \equiv \mathrm{NO}_{\mathrm{y}}-\mathrm{NO}_{\mathrm{x}}$, were done for $\mathrm{CO}$ to test this hypothesis for the conditions of GABRIEL (Appendix B). Finally, organic acids, not measured during GABRIEL, were neglected in the reference run. This assumption was again checked in the sensitivity study. The mean measured temperature and pressure used for the Lagrangian model runs are $25.9^{\circ} \mathrm{C}$ and $966 \mathrm{hPa}$, respectively.

The remainder of the trace gases and the species studied were freely calculated and recorded every $5 \mathrm{~min}$. Contrary to Stickler et al. (2006), this includes PAN and MPAN (peroxymethacryloyl nitrate) because of their much shorter chemical lifetime (about $50 \mathrm{~min}$ at $25^{\circ} \mathrm{C}$; Finlayson-Pitts and Pitts, 2000) compared to the upper troposphere.

Each complete model simulation consisted of 57 single model runs with slightly changed initial conditions following the "equivalent longitude" concept introduced in Stickler et al. (2006), accounting for non-linear effects of photochemistry associated with the variance of the sampling time:

$\operatorname{lon}_{\text {eq. }}=(\overline{\text { local time }}-$ model time $) \cdot \frac{360^{\circ}}{24 \cdot 3600 \mathrm{~s}}+\Delta \operatorname{lon}_{\text {eq. }}$

where

$\Delta \operatorname{lon}_{\text {eq. }}=k \cdot 1.25^{\circ}$

and

$k=-\sigma($ local time $) \cdot \frac{360}{24 \cdot 3600 \mathrm{~s}} \cdot 1.25, \ldots,+\sigma \ldots$

For this study, the equivalent longitude was calculated as $(12.4 \pm k \cdot 1.25)^{\circ}, k=0 \ldots .28$, reflecting the $1 \sigma$ empirical standard deviation of the local time for all flight data below $1 \mathrm{~km}$ altitude in the pure ocean bin between $51^{\circ} \mathrm{W}$ and $52^{\circ} \mathrm{W}$. This corresponds to a mean local time of about 12:50 LT. As no clear longitudinal gradient of the radiation measurements could be detected, this time was allocated to the arithmetic mean of all $J\left(\mathrm{NO}_{2}\right)$ values measured below $1 \mathrm{~km}$. The diurnal cycle of the $J$-values was then calculated as in Stickler et al. (2006), using

$\overline{\mid 43200 \mathrm{~s}-\text { local time } \mid}=35411 \mathrm{~s}$

and a mean latitude of $4.672^{\circ}$ for the calculation of the diurnal maximum, and assuming a proportionality with the sine of the solar elevation angle. To be able to interpret the model results, arithmetic means of the 57 values of the examined variables computed at a model time of $24 \mathrm{~h}$ were calculated. This procedure optimises the comparability of the model results and the measurements.

\subsection{Specific settings in the "steady state" mode}

In the case of $\mathrm{HCHO}$ and $\mathrm{H}_{2} \mathrm{O}_{2}$ (only over the ocean) the box model was also used in a "steady state" mode allowing for the assessment of the chemical equilibrium of shorter lived species like $\mathrm{HCHO}$, and for the investigation of $\mathrm{H}_{2} \mathrm{O}_{2}$ dry deposition in the relatively aged air masses arriving from the east over the ocean.

For this purpose 6 segments from the 2 flights (G04 and G07) over the ocean and the continental region in the eastern part of the operating area (see Fig. 1) were selected. These 2 flights offered the advantage that each included $3 \mathrm{BL}$ flight legs, one above the ocean and two above the rainforest, and the flight paths were nearly identical. The flight legs were termed "Gxxa", "Gxxb" and "Gxxc" with the flight number $\mathrm{xx}$ and $\mathrm{a}, \mathrm{b}, \mathrm{c}$ for the eastern (ocean), middle (rainforest) and western (rainforest) flight leg.

For each case the mean equivalent longitude, Eq. (2) and the parameter $k$ were evaluated. As the studied flight segments were quite short, generally about $15 \mathrm{~min}$, the absolute value of $k$ was always less than 3 , equivalent to a variation of $\pm 15 \mathrm{~min}$ in local time. Accordingly, the variation of the initial boundary conditions could be turned down since no significant nonlinear averaging effects are expected (see discussion in Stickler et al., 2006).

Mean values of static air pressure, temperature, latitude and the photolysis rates were calculated for each case. Additionally, the average mixing ratios of the measured trace gases were evaluated for the respective time periods. By visual inspection of all time series, single pollution "plumes" were ruled out. There was only one event during flight G07 when NO volume mixing ratios showed a strong rise and several peaks over the ocean for at least 15 min without a corresponding signal in $\mathrm{CO}$ or other species. This part of the measurements has been excluded from the present study. In the case of NO median instead of mean mixing ratios were implemented because sharp peaks in the NO data do not adequately represent the chemical conditions above the ocean and the rainforest environment, typically poor in $\mathrm{NO}_{\mathrm{x}}$, and would lead to an artificial overestimation of HCHO due to the strong sensitivity of this compound towards NO (Stickler et al., 2006).

In the case of $\mathrm{H}_{2} \mathrm{O}$ there was no data available for flight G07 so that the mixing ratios were assumed to be the same in the eastern, middle and western part of the longitudinal transects as during flight G04. This assumption does not significantly influence the results of the study as $\mathrm{H}_{2} \mathrm{O}$ does not play a major role for the chemistry in the box model when $\mathrm{OH}$ and $\mathrm{HO}_{2}$ are constrained by measurements. Radiation measurements were not available for $\mathrm{G} 07 \mathrm{c}$ so that photolysis rates were assumed to be the same as in case G07b. Since methanol, acetone and isoprene were not measured during $\mathrm{G} 07 \mathrm{c}$, it was assumed that

$\frac{x_{s}(\mathrm{G} 07 \mathrm{~b})}{x_{S}(\mathrm{G} 07 \mathrm{c})}=\frac{x_{s}(\mathrm{G} 04 \mathrm{~b})}{x_{S}(\mathrm{G} 04 \mathrm{c})}$

with the mixing ratio $x$ of the species $s$ involved. This seems reasonable because segments G04b and G04c are located in the same region as G07b and G07c, respectively. Finally, for flight G07 only total peroxide data is available. From this data and the $\mathrm{BL}$ ratio of the medians $\mathrm{H}_{2} \mathrm{O}_{2} /$ org. peroxide 
resolved in longitudinal bins of $1^{\circ}$ for the whole campaign data, the values were inferred assuming these ratios were also valid during flight G07. The organic peroxides were subdivided into $\mathrm{CH}_{3} \mathrm{OOH}$, ISOOH and MVKOOH by assuming measured organic peroxide over the ocean to consist only of $\mathrm{CH}_{3} \mathrm{OOH}$ and keeping its mixing ratio constant over land, similar with the procedure for the Lagrangian mode. As in the Lagrangian case sensitivity runs were done with altered partitioning. For isoprene, $\mathrm{MVK}, \mathrm{Cl}, \mathrm{OH}$ and $\mathrm{HO}_{2}$ diurnal cycles identical to the ones described for the Lagrangian mode were prescribed. The one for NO was changed for the oceanic segments such that the morning peak in the median of all BL data of about $50 \mathrm{pmol} / \mathrm{mol}$ was filtered out, since this peak is a typical feature produced by the lifting of the $\mathrm{BL}$ over land and the photolysis of $\mathrm{NO}_{2}$ having accumulated during nighttime. The concentrations of all other measured species were kept constant. The model run was stopped after the daily change of $\mathrm{HCHO}$ had reached less than $0.01 \%$ $(\approx 30-50$ days in the case of $\mathrm{HCHO}$ ).

\subsection{Determination of the BL height}

For all model runs explicitly including the effect of dry deposition it was necessary to obtain an estimate of the BL height. These include the "steady state" and Lagrangian calculations of $\mathrm{HCHO}$, the runs for the assessment of the $\mathrm{H}_{2} \mathrm{O}_{2}$ dry deposition velocity and the Lagrangian run calculating the time development of the organic peroxides along the examined trajectory.

This estimate is based on the diagnostic BL height from simulations with a single-column model (SCM) version of the global 3-D chemistry-climate model ECHAM4 (Roeckner et al., 1996, 1999; Ganzeveld et al., 2002, 2006a,b). The 1-D SCM has also been applied to study the BL chemistry during the GABRIEL campaign in greater detail ${ }^{2}$. The trajectory of the SCM starting at $45^{\circ} \mathrm{W} 4.5^{\circ} \mathrm{N}$ shows that the $\mathrm{BL}$ height over the ocean is roughly constant over time so that a fixed value of $570 \mathrm{~m}$ (mean BL height for $50-51^{\circ} \mathrm{W}$ ) was chosen. As expected, above land the model results show a strong diurnal variation with a minimum BL height during nighttime $(\approx 60-120 \mathrm{~m})$ and a maximum during daytime $(\approx 1100 \mathrm{~m})$. Consequently, a diurnal cycle was derived by fitting a 3rd order polynomial to the data. According to these results the BL height over land exceeded $500 \mathrm{~m}$ between 08:45 LT and 18:15 LT.

In the 6 cases described above, the flight altitudes in the BL were about: $330 \mathrm{~m}(\mathrm{G} 04 \mathrm{a}), 500-510 \mathrm{~m}$ (G04b), 385$660 \mathrm{~m}$ (G04c), $325 \mathrm{~m}$ (G07a), 375-490 m (G07b) and 380$485 \mathrm{~m}(\mathrm{G} 07 \mathrm{c})$. Flight G04 was conducted in the early afternoon at a time of the day when the BL height is predicted to be at maximum. In contrast, flight G07 was performed in the morning hours. The earliest local time dur-

\footnotetext{
${ }^{2}$ Ganzeveld et al.: Atmos. Chem. Phys. Discuss., in preparation, 2007.
}

ing the measurements between $0-1 \mathrm{~km}$ a.s.l. over land is (08:55 LT $\pm 5 \mathrm{~min})$. The aircraft was therefore clearly located in the BL during flight G04 when flying the segments examined with the "steady state" model, while for flight G07 it cannot be ruled out that the aircraft was situated just above the growing BL and inside the residual BL. Nevertheless, low ozone mixing ratios of $<15 \mathrm{nmol} / \mathrm{mol}$, similar to the ones measured in the marine $\mathrm{BL}$ on the same day compared to $27-50 \mathrm{nmol} / \mathrm{mol}$ and higher at $\approx 1-3 \mathrm{~km}$ a.s.l. argue against this. Additionally, sharp peaks in the $\mathrm{CO}$ data in the range 2-3 km point towards a relatively strong inversion layer and the NO data shows generally enhanced mixing ratios with peaks up to 290 (G07b) and $150 \mathrm{pmol} / \mathrm{mol}(\mathrm{G} 07 \mathrm{c})$, respectively. Finally, the flight altitude is referenced to the sea and not the land surface so that it is an upper limit of the altitude above ground. Hence, from the synopsis of all information available it appears likely that these measurements were also taken in the BL. For the Lagrangian studies using all flight data, the largest part of the data in the altitude range $0-1 \mathrm{~km}$ were taken in the BL as $80 \%$ of the flights took place at noon or in the afternoon before sunset.

\subsection{HCHO deposition velocity}

To test the representation of the organic chemistry and to cross-check the box model results for CO (see Sect. 4), "steady state" and Lagrangian model runs for $\mathrm{HCHO}$ were performed. In the BL dry deposition has to be included for $\mathrm{HCHO}$, even though its chemical lifetime can be relatively short depending on the solar radiation and the $\mathrm{OH}$ radical concentration. The explicitly calculated dry deposition velocity for a reference altitude of $34 \mathrm{~m}$ above ground from the 1-D SCM was taken as best guess for this parameter, resulting in a constant value of $v_{d}(\mathrm{HCHO}) \approx 0.36 \mathrm{~cm} / \mathrm{s}$ above the ocean and a diurnal cycle above the rainforest (minimum $0.05 \mathrm{~cm} / \mathrm{s}$, maximum $1.1 \mathrm{~cm} / \mathrm{s}$ ), derived as $3 \mathrm{rd}$ order polynomial fit of the SCM data. The SCM includes the turbulent transfer to the surface, molecular diffusion calculated explicitly from the SCM's micrometeorology and uptake by leaf stomata and other substrates including the soil, wet and dry cuticula and oceans. The estimated uptake resistances are based on solubility and reactivity of the trace gases.

\subsection{Halogen chemistry}

In the oceanic segments of the "steady state" model runs, chlorine radical chemistry was included to test the sensitivity of formaldehyde formation to halogen chemistry in the tropical marine BL. At $\mathrm{Cl}$ concentrations of $1 \times 10^{4} \mathrm{~cm}^{-3}$ the chemical lifetime of alkanes and alkynes towards this species is similar as that towards $\mathrm{OH}$ radicals $\left(1 \times 10^{6} \mathrm{~cm}^{-3}\right)$ (Finlayson-Pitts and Pitts, 2000). Results of measurements and estimates of chlorine radical concentrations in the marine $\mathrm{BL}$ of the tropics as well as the midlatitudes range two orders of magnitude $\left((0.25 \ldots 30) \times 10^{4} \mathrm{~cm}^{-3}\right.$, Singh et al., 1996; 
Wingenter et al., 1996; Lowe et al., 1999; von Glasow et al., 2002; Chang et al., 2004; Platt et al., 2004). Therefore a Cl concentration of $1 \times 10^{4} \mathrm{~cm}^{-3}$ was implemented in the reference run while additional sensitivity runs with the upper and lower limits were performed.

The sensitivity of HCHO towards chlorine radicals was found to be minor in the low range $\left((0.25 \ldots 1) \times 10^{4} \mathrm{~cm}^{-3}\right)$ whereas it gradually increases in the higher concentration range $\left.(1 \ldots 30) \times 10^{4} \mathrm{~cm}^{-3}\right)$. This is due to the facts that a) the $\mathrm{Cl}$ chemistry of non-methane organic compounds (NMOCs) except $\mathrm{HCHO}$ and $\mathrm{CH}_{3} \mathrm{OOH}$ is not included in MECCA $\mathrm{v} 0.1 \mathrm{p}, \mathrm{b})$ inclusion of $\mathrm{Cl}$ chemistry seems to have similar effects on the production and the destruction terms of $\mathrm{HCHO}$ and c) all measured species except HCHO are constrained by the observations. Therefore, halogen chemistry was neglected in the Lagrangian HCHO model run. Sensitivity runs with different $\mathrm{Cl}$ concentrations up to $30 \times 10^{4} \mathrm{~cm}^{-3}$ over the ocean revealed no significant dependence of hydrogen peroxide on halogen chemistry.

\section{Results and discussion}

We use measurements of $\mathrm{CO}, \mathrm{HCHO}, \mathrm{H}_{2} \mathrm{O}_{2}$ and organic peroxides to constrain parameterisations of three major physical and chemical processes: entrainment of FT air, dry deposition, and VOC oxidation mechanisms. Because chemistry and deposition likely affect $\mathrm{H}_{2} \mathrm{O}_{2}$ and $\mathrm{HCHO}$ to a much greater extent than $\mathrm{CO}$, the latter trace gas is first used to determine a consistent entrainment rate. Subsequently, that entrainment rate is used to constrain estimates of the deposition velocity of $\mathrm{H}_{2} \mathrm{O}_{2}$ and the chemistry affecting organic peroxides.

\subsection{Measured longitudinal gradients}

The mixing ratios of several trace gases measured show longitudinal gradients between $0-1 \mathrm{~km}$ a.s.l. generally with an increase from east to west, i.e. from the ocean to the rainforest. Analysing longitudinal transects of the median mixing ratios for the whole data set in the BL we find the following tendencies:

- For CO (Fig. 2) a clear and significant eastwest increase is observed: values generally below $100 \mathrm{nmol} / \mathrm{mol}$ are found in the BL over the easternmost ocean bin (50\% of all measured values lie between 80 and $95 \mathrm{nmol} / \mathrm{mol}$ ) while higher values were measured over land (up to $115-130 \mathrm{nmol} / \mathrm{mol}$ in the westernmost bin). The horizontal $\mathrm{CO}$ gradient is nearly twice as strong $\left(30(\mathrm{nmol} / \mathrm{mol}) / 560 \mathrm{~km} \approx 54 \mathrm{pmol} / \mathrm{mol} \mathrm{km}^{-1}\right)$ compared to LBA-CLAIRE98 $\left(29 \mathrm{pmol} / \mathrm{mol} \mathrm{km}^{-1}\right.$; Williams et al., 2001a).

- For $\mathrm{O}_{3}$ no unequivocal tendency was found for the mean, but rather for the median mixing ratios (Fig. 3), mainly due to low outliers in the westernmost bin over the rainforest. The mixing ratios of this trace gas are characterised by a relatively low median of $14 \mathrm{nmol} / \mathrm{mol}$ in the easternmost bin (ocean), whereas significantly higher medians were found in the west (up to $19.5 \mathrm{nmol} / \mathrm{mol}$ ). A region that stands out for $\mathrm{O}_{3}$ (and also $\mathrm{NO}$ and perhaps $\mathrm{H}_{2} \mathrm{O}_{2}$ ) is the coastal region of French Guyana (transitions from ocean to land were generally located around $52^{\circ} \mathrm{W}$ ) with a median of $18.5 \mathrm{nmol} / \mathrm{mol}$ and highly variable mixing ratios. The fact that $10 \%$ of the data lie above $29 \mathrm{nmol} / \mathrm{mol}$ probably indicates an anthropogenic influence in this relatively densely populated region compared to the practically uninhabited rainforest regions.

- Despite the relatively low precision of the measurements of $25 \%$ at $1.0 \mathrm{nmol} / \mathrm{mol}$, a significant tendency can be seen for $\mathrm{HCHO}$ with median mixing ratios from $429 \mathrm{pmol} / \mathrm{mol}$ in the pure ocean bin to $1873 \mathrm{pmol} / \mathrm{mol}$ in the westernmost bin over the rainforest (Fig. 4).

- Organic peroxides (Fig. 5) also show a distinct increase of the median mixing ratio with lowest values over the ocean $(594 \mathrm{pmol} / \mathrm{mol})$, steadily increasing to $1088 \mathrm{pmol} / \mathrm{mol}$ above the western rainforest area.

Median instead of mean values were used to filter sharp peaks and outliers visible e.g. in the NO data as a result of local sources of the trace gases, not considered in this study.

\subsection{Determination of consistent model entrainment rates} over ocean and land for $\mathrm{CO}, \mathrm{HCHO}$ and $\mathrm{H}_{2} \mathrm{O}_{2}$

Figure 6 shows the expected $\mathrm{CO}$ mixing ratios along the trajectories, i.e. the mixing ratios obtained by superimposing the measured longitudinal gradients and diurnal cycles as described in Sect. 3.2, and taking into account the different starting times according to the varying $k$ values $(\approx 10: 30-15: 15$ LT $)$. The measured median CO mixing ratio at $51.5^{\circ} \mathrm{W}$, the starting mixing ratio for both the expected and the modelled $\mathrm{CO}$ along the trajectories, is $85.6 \mathrm{nmol} / \mathrm{mol}$. The measured (and expected) mixing ratio at $55.86^{\circ} \mathrm{W}$ corresponding to $24 \mathrm{~h}$ transport time is $109.8 \mathrm{nmol} / \mathrm{mol}$. In contrast to this the model results of the reference run give an average of only $88.3 \mathrm{nmol} / \mathrm{mol}$ (Fig. 6).

While the expected difference of the starting and ending mixing ratios is $\Delta \mathrm{CO}=24.2 \mathrm{nmol} / \mathrm{mol}$, corresponding to a longitudinal gradient of $50.0 \mathrm{pmol} / \mathrm{mol} \mathrm{km}^{-1}$, the model indicates only an increase of $\Delta \mathrm{CO}=2.7 \mathrm{nmol} / \mathrm{mol}$ or $5.6 \mathrm{pmol} / \mathrm{mol} \mathrm{km}^{-1}$ by chemical sources. Table 4 presents the analysis of all three flights with available CO measurements conducted towards the east in the BL over ocean and rainforest. This analysis suggests longitudinal gradients of $\mathrm{CO}$ between $16-48 \mathrm{pmol} / \mathrm{mol} \mathrm{km}^{-1}$, being variable and rather smaller than the one derived from the median of all flights, but still significantly larger than the value 
Table 4. Median measured CO longitudinal gradients during flights G03, G04 and G07; the median at $55.86^{\circ} \mathrm{W}$ was derived by a linear interpolation of the values at $55^{\circ} \mathrm{W}$ and $56^{\circ} \mathrm{W}$.

\begin{tabular}{llll}
\hline Flight & G03 & G04 & G07 \\
\hline Median CO $51.5^{\circ} \mathrm{W}[\mathrm{nmol} / \mathrm{mol}]$ & 102.0 & 95.1 & 82.2 \\
Median CO 55.86 W $[\mathrm{nmol} / \mathrm{mol}]$ & 109.7 & 110.7 & 105.6 \\
$\overline{\Delta \mathrm{CO} / \Delta x}\left[\mathrm{pmol} / \mathrm{mol} \mathrm{km}^{-1}\right]$ & 16 & 32 & 48 \\
\hline
\end{tabular}

$5.6 \mathrm{pmol} / \mathrm{mol} \mathrm{km}^{-1}$ predicted by the Lagrangian model without FT entrainment and soil sources. As in the study by Williams et al. (2001a) of measurements during the LBACLAIRE campaign, the $\mathrm{CO}$ mixing ratios in the BL over the ocean exhibit quite strong day-to-day variability $(\approx 82-$ $102 \mathrm{nmol} / \mathrm{mol})$, stronger than over the rainforest $(105.6$ $110.7 \mathrm{nmol} / \mathrm{mol}$ ), and indicating changes in the composition of air advected to the coast.

To make sure that the calculated gradient is not artificially enhanced by these changing "background" conditions, we searched for a near-Lagrangian case and found one between different legs of flight G03 and G04. The measurements in the easternmost part of the eastern boundary layer leg during G03 (6 October 2005) and the western boundary layer leg during G04 (7 October 2005) appear closest to a Lagrangian event, with the projected position of the air mass analysed during G03 about $100 \mathrm{~km}$ west of the flight track during G04. For this case $\Delta \mathrm{CO} \approx 7.7 \mathrm{nmol} / \mathrm{mol}$ in $22 \mathrm{~h}$ transport time corresponding to a gradient of $17.5 \mathrm{pmol} / \mathrm{mol} \mathrm{km}^{-1}$, similar to the smallest gradient calculated before. Again, it is significantly larger than in the model, confirming the earlier results.

Provided that the chemistry in the mechanism is represented correctly these results imply that there must be other sources significantly influencing $\mathrm{CO}$. In principle these can be a) direct emission of $\mathrm{CO}$, e.g. by biomass burning or from the soil, or b) mixing-in from above the BL of free tropospheric air richer in $\mathrm{CO}$ or c) other chemical sources not in the model could be present, e.g. terpenes/sesquiterpenes.

To ensure the robustness of our results with respect to the chemistry a sensitivity study was conducted (see Appendix B). Allowing for the examined realistic variations of the different chemical parameters, caused by measurement errors and other uncertainties, we can conclude from this analysis that the uncertainties connected to the measurements/estimates of the different precursors of $\mathrm{CO}$ are not large enough to explain the discrepancy between the measured and modelled longitudinal gradient.

\subsubsection{Biomass burning and surface sources}

ABBA (Automated Biomass Burning Algorithm) fire maps prepared from GOES-12 satellite images of South America (Cooperative Institute for Meteorological Satellite Stud-
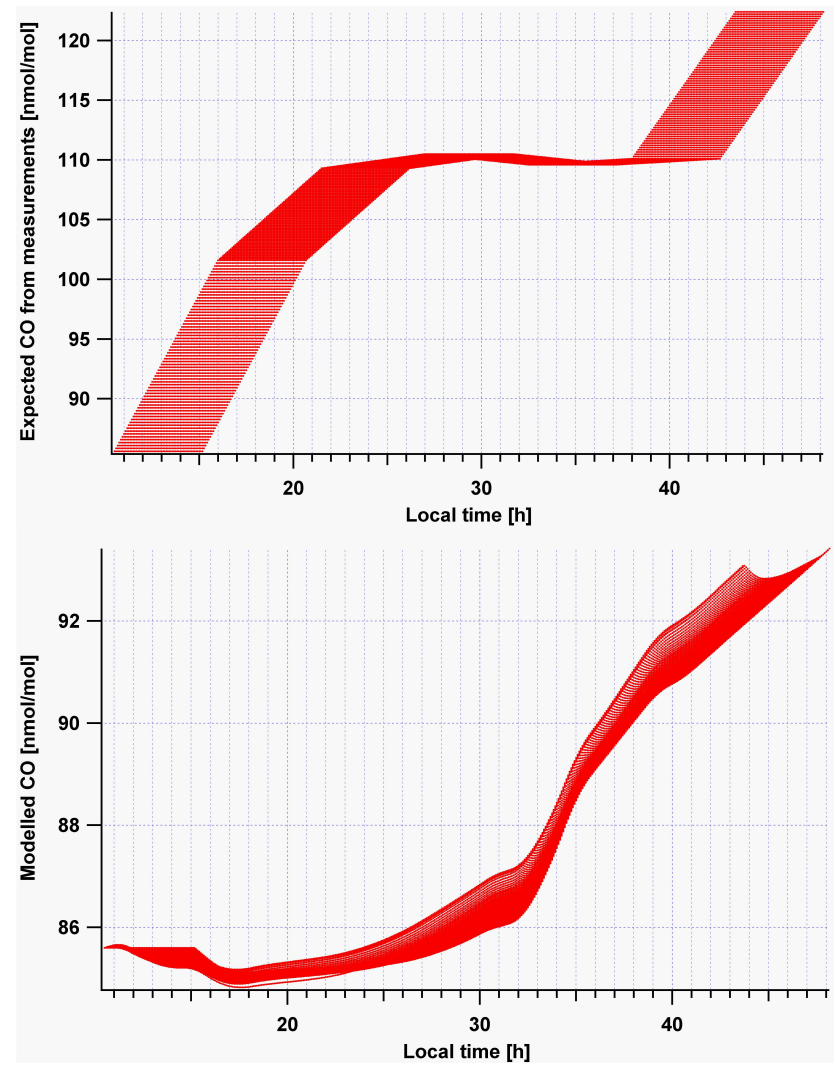

Fig. 6. Upper panel: Expected $\mathrm{CO}$ mixing ratios along the 57 different trajectories prescribed by the varying $k$ values; the variation of the mixing ratio as a function of local time arises solely from the measured longitudinal gradient, superimposed by the effect of the different starting times of the trajectories. Lower panel: CO mixing ratios calculated along the 57 different trajectories with the box model (Lagrangian mode, reference run).

ies (CIMSS), http://cimss.ssec.wisc.edu/goes/burn/wfabba. html) show no evidence of forest fires or significant biomass burning directly in the region where the measurements took place (Guyanas). Biomass burning was generally only detected south or west of this region in deforested parts of the Guyana Highlands in northern Brazil south of the Surinamese border, in the region of Boa Vista (Roraima, Brazil) and especially in eastern Venezuela (region around Ciudad Guayana). In these cases the wind direction in the BL precludes a possible influence of the fires on our measurements. An exception is 15 October 2005 (flight G10) when fire activity was observed along the coast of French Guyana and in northern Guyana. Nevertheless, no influence of these fires on the $\mathrm{CO}$ mixing ratio can be seen in the BL data obtained over Suriname, i.e. in the form of enhanced volume mixing ratios. On the contrary the mixing ratios measured over the western part of Suriname are higher than the ones from the eastern part of the country, being closer to the fires in French Guyana, thus confirming the general east-west gradient. Visual observations of the operators on board the aircraft 
indicate only one fly by past a biomass burning plume over French Guyana at 16:14 UTC on 7 October 2005 (G04), not reflected in the $\mathrm{CO}$ data, and the crossing of a smoke plume at about 16:20 UTC on 8 October 2005 (G05), matching a sharp peak up to almost $160 \mathrm{nmol} / \mathrm{mol}$.

In some occasions the $\mathrm{BL} \mathrm{CO}$ mixing ratios (75$135 \mathrm{nmol} / \mathrm{mol}$, peaks during flights $\mathrm{G} 05$ and $\mathrm{G} 08$ up to $170 \mathrm{nmol} / \mathrm{mol}$ ) were comparable or higher than the mixing ratios in the FT. During flights G03, G04, G05 (only partly), G07 and G08 significantly higher mixing ratios were detected above the BL between $2-3 \mathrm{~km}$ altitude though (no $\mathrm{CO}$ data is available for flight G06). During G03 a maximum CO mixing ratio was found at an altitude of 2500 $3000 \mathrm{~m}$ a.s.l. with maximum differences of $\approx 6-20 \mathrm{nmol} / \mathrm{mol}$ between BL and FT mixing ratios. Yet the average difference of the layers $0-1$ and $1-3 \mathrm{~km}$ a.s.l. is only $1.6 \mathrm{nmol} / \mathrm{mol}$ as the mixing ratio decreases again above this relatively thin layer of enhanced CO. For G04 a much more elevated mean difference of these layers of $18 \mathrm{nmol} / \mathrm{mol}$ was found, whereas the enhancement, at least over the continent, was again concentrated in a thin layer at about $2500 \mathrm{~m}$ a.s.l. $\mathrm{CO}$ data from $\mathrm{G} 07$ shows peaks up to $270 \mathrm{nmol} / \mathrm{mol}$ at about $3 \mathrm{~km}$ altitude and data from G08 exhibits a maximum of approximately $140 \mathrm{nmol} / \mathrm{mol}$ at about $2 \mathrm{~km}$ altitude. Fire maps (see also MODIS data on http://rapidfire.sci.gsfc. nasa.gov/firemaps), trajectory (KNMI/ECMWF and NOAA, http://www.arl.noaa.gov/ready/hysplit4.html) as well as 3-D Chemistry Transport Model (CTM) calculations (MATCHMPIC; M. G. Lawrence, private communication) suggest that these enhancements in $\mathrm{CO}$ could originate from biomass burning in western or southern central Africa and partly also in other parts of South America south of the Guyanas. MODIS fire maps for this period show fires e.g. in eastern Brazil, Mauretania/Mali and Congo/western and southern Democratic Republic of Congo/Angola/Sambia. Chatfield et al. (1998) have proposed a mechanism for the intercontinental export of $\mathrm{CO}$ in the middle troposphere up to $5.5 \mathrm{~km}$ altitude from Africa to South America based on deep mixing from the BL up to altitudes of $2.5-5 \mathrm{~km}$ over Africa and lofting over the monsoon inflow of the equatorial African coast, termed the "Great African CO Plume". They report a very intense transport of $\mathrm{CO}$ along this pathway with alternate phases of higher and lower mixing ratios travelling slowly from east to west in October 1994. In that year the main transport took place further south at about $5^{\circ} \mathrm{S}$ though.

Several authors have reported carbon monoxide fluxes from different soil types. Sanhueza et al. (1994) report measurements from nonperturbed savannah grasslands in Venezuela obtained with an enclosed chamber technique, and find that this soil type is a net source of $\mathrm{CO}$ $\left(3.4 \times 10^{10} \mathrm{~cm}^{-2} \mathrm{~s}^{-1}\right)$. The same technique had already been used by Conrad and Seiler (1985) for measurements in Spain, South Africa and the Namibian desert. The maximum flux derived was $\approx 1.3 \times 10^{11} \mathrm{~cm}^{-2} \mathrm{~s}^{-1}$ under midlatitude conditions with dry, carbon-rich soil in Germany although the study predicts probably even higher fluxes from warm and carbon-rich soils as in the rainforests. Kirchhoff and Marinho (1990) estimated a CO flux of $4 \times 10^{11} \mathrm{~cm}^{-2} \mathrm{~s}^{-1}$ from the Amazonian rainforest during the wet season by means of vertical gradient measurements at a tower near Manaus. A comparable value for the mean emission flux of $\approx 4.36 \times 10^{11} \mathrm{~cm}^{-2} \mathrm{~s}^{-1}$ is derived from the model study of Tao and Jain (2005). Additionally, field and laboratory studies suggest that $\mathrm{CO}$ is not only emitted by dead plant matter but also by live leaves (Scharffe et al., 1990; Tarr et al., 1995). Scharffe et al. (1990) estimated a CO flux from termites and vegetation of $5 \times 10^{10} \mathrm{~cm}^{-2} \mathrm{~s}^{-1}$ in a scrub grass savannah in Venezuela. However, one should keep in mind that these flux estimates are associated with relatively large uncertainties.

When taking into account a height of the mixed BL of $1100 \mathrm{~m}$ (see Sect. 3.4) and the concentration of air molecules of $2.34 \times 10^{19} \mathrm{~cm}^{-3}$ at $966 \mathrm{hPa}$, the four specified measured fluxes result in a $24 \mathrm{~h}$ increase in the CO BL mixing ratio of $1.1 \mathrm{nmol} / \mathrm{mol}, 4.3 \mathrm{nmol} / \mathrm{mol}, 13.4 \mathrm{nmol} / \mathrm{mol}$ and $1.7 \mathrm{nmol} / \mathrm{mol}$, respectively. Only the largest of these values would, together with photochemical production from VOCs, be sufficient to explain the lower half of the range of observed longitudinal gradients. To match the full range of these gradients a CO emission flux of $1.5 \times 10^{11} \mathrm{~cm}^{-2} \mathrm{~s}^{-1}$ up to $6.1 \times 10^{11} \mathrm{~cm}^{-2} \mathrm{~s}^{-1}$ would be necessary.

To summarise, it is conceivable that $\mathrm{CO}$ soil emissions contribute to the budget of $\mathrm{CO}$ in the $\mathrm{BL}$ over the tropical rainforest and possibly even regionally outbalance the importance of photochemistry for this trace gas. Nevertheless, it remains questionable if the strong horizontal gradient of the $\mathrm{CO}$ mixing ratio can be fully explained by a combination of photochemical processes and soil emissions alone.

4.2.2 Entrainment of air from the free troposphere into the planetary boundary layer

Entrainment of relatively CO-rich FT air into the BL is another possibility to explain the observed strong longitudinal $\mathrm{CO}$ gradient. We assessed the upper limit of the $24 \mathrm{~h}$ average entrainment rate using the mean difference of the mixing ratios in the BL and in the FT, both defined as the layers between $0-1$ and $1-3 \mathrm{~km}$ a.s.l., respectively. This calculation was done for flights G03 and G04, the flights which represent the "Lagrangian" case as described in Sect. 4.2.

As mentioned earlier the longitudinal gradient derived for this case, which can be regarded as the best estimate for the "true" gradient without changes in background $\mathrm{CO}$, was determined to be $\approx 17.5 \mathrm{pmol} / \mathrm{mol} \mathrm{km}^{-1}$ while the model results without emissions and entrainment indicated a gradient of $\approx 5.6 \mathrm{pmol} / \mathrm{mol} \mathrm{km}^{-1}$. We estimate an upper limit of the mean entrainment rate by assuming that the difference of these values (i.e. $11.9 \mathrm{pmol} / \mathrm{mol} \mathrm{km}^{-1}$ ) is caused by mixing-in of air from the FT with a $\mathrm{CO}$ mixing ratio 1.6 and $18 \mathrm{nmol} / \mathrm{mol}$ higher than in the BL. The latter are the average differences between BL and FT mixing ratios 
$\left(\Delta x_{\mathrm{FT}-\mathrm{BL}}\right)$ during flights $\mathrm{G} 03$ and $\mathrm{G} 04$, respectively (see Sect. 4.2.1). At a mean wind speed of $5.6 \mathrm{~m} / \mathrm{s}$ the gradient of $11.9 \mathrm{pmol} / \mathrm{mol} \mathrm{km}^{-1}$ is equivalent to a temporal increase $\Delta x_{\mathrm{BL}} / \Delta t \approx 240 \mathrm{pmol} / \mathrm{mol} \mathrm{h}^{-1}$, larger than the average predicted chemical production rate. If the differences in the mixing ratios are assumed constant, the mean fractional entrainment rate $E R$ can be expressed as

$E R=\frac{\Delta x_{B L} / \Delta t}{\Delta x_{\mathrm{FT}-\mathrm{BL}}}$

i.e. a fraction $E R$ of the $\mathrm{BL}$ air is exchanged with FT air per unit of time. In our case this calculation leads to $E R \approx 0.15 \mathrm{~h}^{-1}$ (G03) and $E R \approx 0.01 \mathrm{~h}^{-1}$ (G04). The discrepancy between the two values for G03 and G04, which results from the different BL-FT gradients of the $\mathrm{CO}$ mixing ratios, is reflected in the vertical gradients of the peroxide mixing ratios during these flights. The latter show a similar behaviour during these two days with a weak gradient during G03 pointing at a well mixed lower troposphere, and a strong gradient during $\mathrm{G} 04$, indicating a layered structure with minor vertical exchange. Consequently, the first value is taken as an upper limit for the $24 \mathrm{~h}$ mean entrainment rate. Figure 7 shows the relative error of the model-derived longitudinal CO gradient versus $E R$ and the average BL-FT difference in the mixing ratios. It is obvious from this plot that the derived $E R$ is strongly dependent on the latter parameter, resulting in a relatively large uncertainty in the estimate without further constraints, coming e.g. from the $\mathrm{HCHO}$ and $\mathrm{H}_{2} \mathrm{O}_{2}$ measurements and giving a consistent picture.

\subsubsection{Further constraints on the entrainment rate from an} analysis of the $\mathrm{HCHO}$ and $\mathrm{H}_{2} \mathrm{O}_{2}$ data

The steady state model described in Sect. 3.3 was applied to predict $\mathrm{HCHO}$ mixing ratios in the six cases defined there. This was done to cross-check the results obtained with the Lagrangian CO model, and particularly to investigate if some organic precursors are missing in the chemical mechanism, which could have been another explanation for the too low predicted $\mathrm{CO}$ mixing ratio. As mentioned earlier, dry deposition of $\mathrm{HCHO}$ was accounted for in this model by using the deposition velocity calculated explicitly with a 1-D SCM and the diagnostic BL height from ECHAM4. Entrainment was not included in these calculations. Instead an upper limit for the daytime entrainment rate was deduced from a Lagrangian model run. The arithmetic means of the measured $\mathrm{HCHO}$ mixing ratios together with model results are listed in Table 5 .

The results show that, contrary to the findings for $\mathrm{CO}$, the mixing ratios of $\mathrm{HCHO}$ are partly drastically overestimated by the "steady state" model in the reference case. Only an unlikely combination of several reduced parameters leads to a better agreement of measurement and model results $(\mathrm{OH}$ $\left.-25 \%, \mathrm{NO}-5 \mathrm{pmol} / \mathrm{mol}, \mathrm{Cl}-75 \%, v_{d}(\mathrm{HCHO})=v_{d}\left(\mathrm{HNO}_{3}\right)\right)$. The explicitly calculated $v_{d}(\mathrm{HCHO})$ from the 1-D SCM sug-

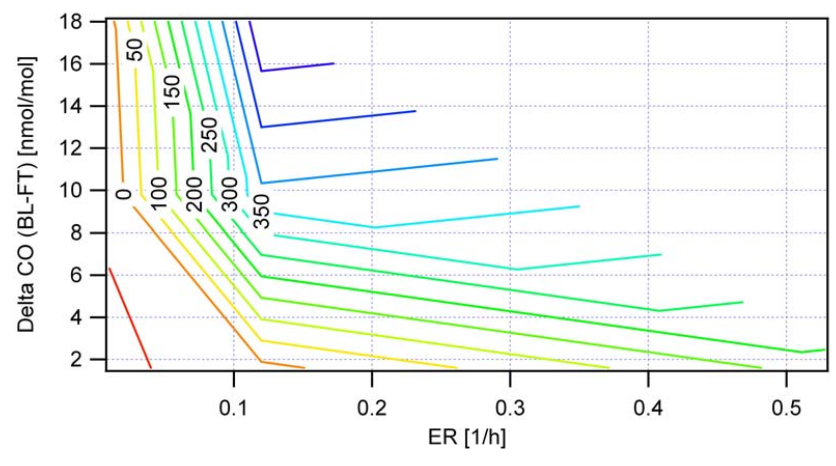

Fig. 7. Contours of the relative error [\%] of the model-derived mean longitudinal $\mathrm{CO}$ gradient versus the entrainment rate and the mean difference in the BL and FT mixing ratios.

gests a significant role of surface removal processes, indicated by a maximum $v_{d}$ smaller than the turbulent exchange velocity. $v_{d}\left(\mathrm{HNO}_{3}\right)$, on the other hand, is removed very efficiently at the surface in the model. By performing this analysis, we have assessed the impact of an upper limit removal efficiency. Assuming normally distributed and statistically independent variables the necessity of the combination of two parameter modifications with $\Delta_{1} \leq-0.5 \sigma$ and $\Delta_{2} \leq-1 \sigma$ alone corresponds to a probability of less than $5 \%$, so that the model-measurement discrepancy is significant on a $95 \%$ basis. Additionally, the calculated MEK and acetaldehyde mixing ratios in the model are at the lower end of measurements during LBA-CLAIRE and other campaigns. This outcome precludes a deficiency in the chemical mechanism as the reason for the discrepancy in the case of $\mathrm{CO}$, at least for all species being oxidised via $\mathrm{HCHO}$ to form $\mathrm{CO}$ and not directly forming $\mathrm{CO}$ by circumventing $\mathrm{HCHO}$ as intermediate.

Since wet deposition is not likely to be very important (Henry constant $k_{H}(\mathrm{HCHO})=6 \times 10^{3} \mathrm{M} / \mathrm{atm}$ at $T=273.15 \mathrm{~K}$, $p=1013.25 \mathrm{hPa}$, http://www.mpch-mainz.mpg.de/ $\sim$ sander/ res/henry.html) and the effect of dry deposition is limited by the deposition velocity of $\mathrm{HNO}_{3}$, this again points to a possible role of BL-FT exchange. An alternative to bring model results and measurements closer together would be heterogeneous removal of $\mathrm{HCHO}$ on aerosol particles. However, this seems unlikely considering the result of de Reus et al. (2005), who found no significant influence of heavy aerosol loading on HCHO in a Saharan dust plume, even though a haze layer above the rainforest was noticed several times by the operators on board the aircraft. Unfortunately, no quantitative aerosol measurements were performed during the GABRIEL campaign. In summary, a significant entrainment from the FT into the BL, perhaps in combination with an underestimation of the dry deposition of HCHO by the 1-D SCM, is consistent with the overprediction of $\mathrm{HCHO}$ in the reference run. It is further consistent with the results of a study on the sensitivity of the optimum $\mathrm{H}_{2} \mathrm{O}_{2}$ dry deposition velocity on the ER (see Sect. 4.3.1 and the upper panel of Fig. 10) 
Table 5. Comparison of the average measured HCHO mixing ratios during the six cases defined in Sect. 3.3 with the steady state mixing ratios predicted by the box model for the reference run and cases with: $\mathrm{OH}$ decreased by $25 \%$; increased $\mathrm{HO}_{2}(25 \%)$; $\mathrm{NO}_{\text {decreased by } 5}$ $\mathrm{pmol} / \mathrm{mol}$; dry deposition velocity increased by $50 \%$ (equivalent to a $\mathrm{BL}$ height decreased by $33.3 \%$ ); $\mathrm{OH}, \mathrm{NO}$ and $\mathrm{Cl}$ decreased (the latter by $75 \%$ ) and dry deposition velocity increased respectively; the model runs were done with yet uncorrected radiation data, however, the reference run including $J$ values with a correction factor of 1.1 gives results only slightly smaller ( $<7 \%)$; the results of case G07c have to be taken with caution since methanol, isoprene and acetone mixing ratios had to be estimated due to lacking PTR-MS data.

\begin{tabular}{|c|c|c|c|c|c|c|}
\hline Case & G04a & G04b & G04c & G07a & G07b & G07c \\
\hline $\mathrm{HCHO} \mathrm{RR}{ }^{2}[\mathrm{pmol} / \mathrm{mol}]$ & 510 & 1492 & 1667 & 701 & 734 & 691 \\
\hline $\mathrm{HO}_{2} \uparrow[\mathrm{pmol} / \mathrm{mol}]$ & 461 & 1301 & 1438 & 650 & 653 & 613 \\
\hline $\mathrm{NO} \downarrow[\mathrm{pmol} / \mathrm{mol}]$ & 377 & 1366 & 1513 & 641 & 641 & 608 \\
\hline $\mathrm{v}_{d} \uparrow(\mathrm{BL}$ height $\downarrow)[\mathrm{pmol} / \mathrm{mol}]$ & 495 & 1434 & 1602 & 638 & 646 & 651 \\
\hline
\end{tabular}

${ }^{1} \mathrm{SD}$ : estimated error (standard deviation) of the mean, calculated as $\sigma_{n-1}(\mathrm{HCHO}) / \sqrt{n}$ with the number of measurement points $n$ on the respective flight segment, ${ }^{2} \mathrm{RR}$ : reference run

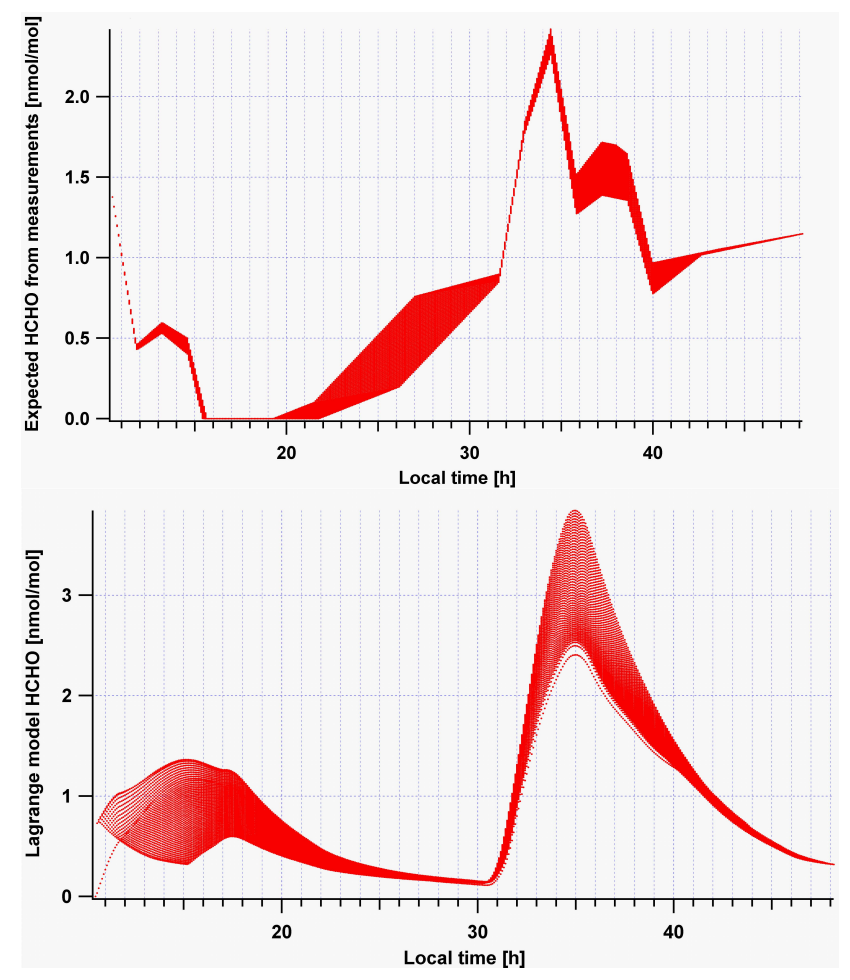

Fig. 8. Upper panel: Expected $\mathrm{HCHO}$ mixing ratios along the 57 different trajectories prescribed by the varying $k$ values; the variation of the mixing ratio as a function of local time arises from the measured longitudinal gradient, the effect of the different starting times of the trajectories and the superimposed diurnal cycle. Lower panel: HCHO mixing ratios calculated along the 57 different trajectories with the box model (Lagrangian mode, reference run). and with the good $\mathrm{CH}_{3} \mathrm{OOH}$ model-measurement agreement when using this ER (see Sect. 4.4 and Fig. 12).

To underpin the results of the steady state model an additional Lagrangian model run for $\mathrm{HCHO}$ was realised. The $\mathrm{CO}$ model using the data from all flights was modified such that $\mathrm{HCHO}$ instead of $\mathrm{CO}$ could be freely calculated. Again HCHO deposition was introduced as described in Sect. 3.5. These computations yield a mean $\mathrm{HCHO}$ mixing ratio of about $2.3 \mathrm{nmol} / \mathrm{mol}$ after $24 \mathrm{~h}$ transport time for all $57 \mathrm{runs}$ of the model compared to about $1.5 \mathrm{nmol} / \mathrm{mol}$ deduced from a linear longitudinal interpolation of the measured medians combined with the observed diurnal cycle (see Fig. 8). The model predicts much higher formaldehyde than was measured, substantiating the earlier conclusions. Figure 9 shows that including entrainment in the model leads to a better agreement of the results with the measurements.

A lower limit for the maximum daytime entrainment rate from the FT into the BL has been determined using the modelled and measured HCHO mixing ratios and the longitude dependent $\mathrm{HCHO}$ mean mixing ratio at $1-3 \mathrm{~km}$ altitude for all flights. It is assumed that the chemical lifetime

$\tau_{\mathrm{HCHO}, \text { daytime }}(\approx 1 \mathrm{~h}) \stackrel{!}{=} \tau_{\text {entrain }}$

where

$\tau_{\text {entrain }}:=\frac{\mathrm{HCHO}_{\text {meas BL }}-\mathrm{HCHO}_{\text {model, } 24 \mathrm{~h}}}{\left(\mathrm{HCHO}_{\text {meas FT }}-\mathrm{HCHO}_{\text {model, } 24 \mathrm{~h}}\right) \cdot E R}$

so that the influence of the entrainment on the HCHO mixing ratio would be equal to that of the chemistry. Here $\mathrm{HCHO}_{\text {meas }} \mathrm{BL}$ is the linearly interpolated measured median of the $\mathrm{HCHO}$ mixing ratio at $55.86^{\circ} \mathrm{W}, \mathrm{HCHO}_{\text {model, } 24 \mathrm{~h}}$ is the model predicted mixing ratio in the $\mathrm{BL}$ after $24 \mathrm{~h}$ runtime and $\mathrm{HCHO}_{\text {meas }} \mathrm{FT}$ is the mean measured mixing ratio 


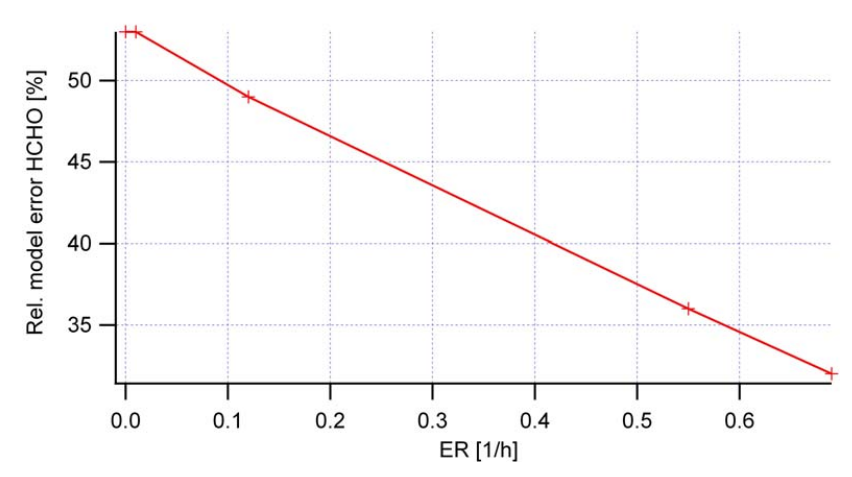

Fig. 9. Estimated upper limit relative error of the HCHO mixing ratio after $24 \mathrm{~h}$ transport time calculated with the Lagrangian model. The estimate was calculated assuming an "effective" time of $1 \mathrm{~h}$ for entrainment, similar to the chemical lifetime in the model.

in the above defined FT. This calculation is based on the idea that only mixing processes with a characteristic mixing time of the same magnitude or smaller than the chemical lifetime of the examined species will strongly influence the mixing ratio of the species. Evaluating the equation leads to $\max \left(E R_{\text {daytime }}\right)>0.55 \mathrm{~h}^{-1}$.

A second estimate for this parameter has been obtained from the steady state model using the mean daylight hour difference of the HCHO mixing ratios in the BL and in the FT during flight $\mathrm{G} 04$ and the steady state mixing ratio calculated for case G04c. This results in $\max \left(E R_{\text {daytime }}\right)>0.69 \mathrm{~h}^{-1}$.

In conclusion, the $E R$ values derived from the $\mathrm{HCHO}$ measurements are clearly higher than the $24 \mathrm{~h}$ averages derived from the $\mathrm{CO}$ data and imply effective mixing-in of FT air into the $\mathrm{BL}$ on timescales smaller than the lifetime of $\mathrm{HCHO}$ during daylight. This argument is valid if entrainment is considered to be the only loss process besides gas phase chemistry and dry deposition. On the other hand, the significant vertical gradients in $\mathrm{CO}$ between the $\mathrm{BL}$ and the FT observed during several flights argue against a continuous efficient daytime entrainment. As noted before, the calculation of the entrainment rate makes use of the HCHO dry deposition rate computed explicitly with a 1-D SCM. The latter is similar to the predicted dry deposition rate of $\mathrm{HNO}_{3}$ over the ocean but much smaller over land (maximum of the diurnal cycle of $1.1 \mathrm{~cm} / \mathrm{s}$ compared to $\approx 2.6 \mathrm{~cm} / \mathrm{s}$ ). Furthermore, the model-estimated dry deposition of HCHO seems to be relatively small compared to values found e.g. by Krinke (1999) for a forest in Germany, particularly when allowing for the extrapolated effect of a higher temperature in Suriname. More efficient dry deposition would lead to a smaller estimated $E R$. On the other hand, Rottenberger et al. (2004) report dry deposition velocities of $0.16 \mathrm{~cm} / \mathrm{s}$ in the wet-to-dry season above two different canopy species typical for South American lowland rainforests (in this case the measurements indicate less efficient deposition than in our model), and Sumner et al. (2001) report $(0.65 \pm 0.36) \mathrm{cm} / \mathrm{s}$
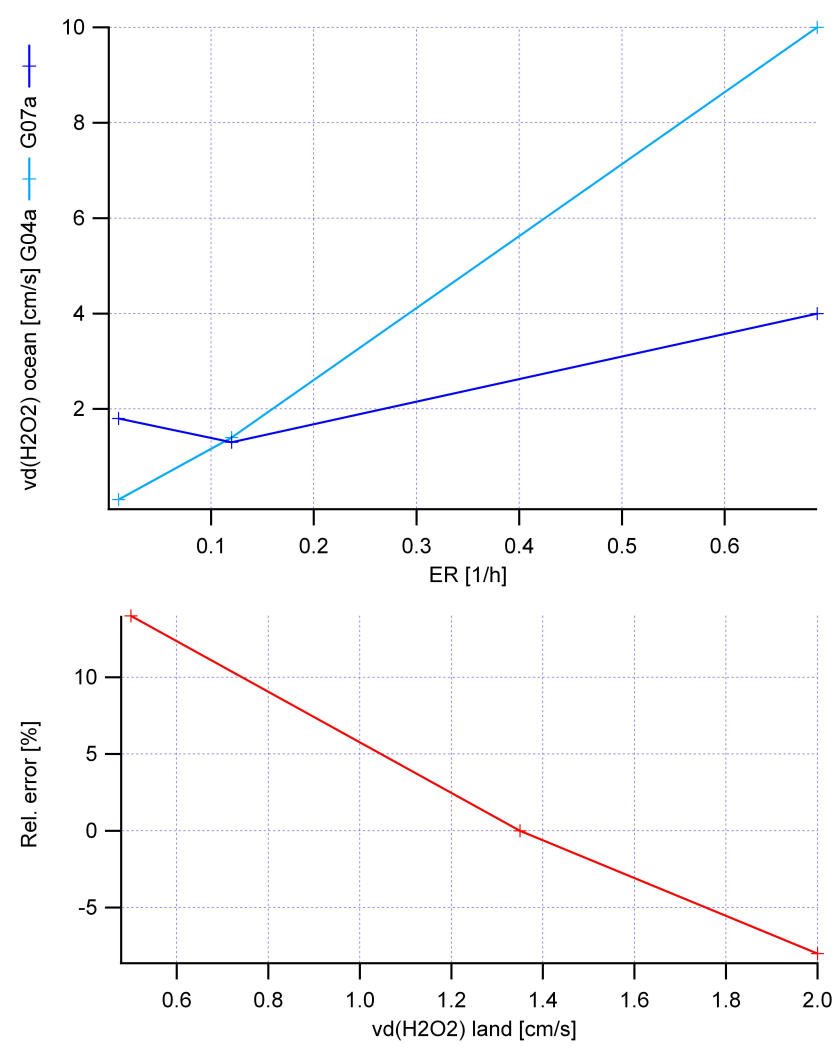

Fig. 10. Upper panel: Dependency of the derived optimum dry deposition velocity $v_{d}\left(\mathrm{H}_{2} \mathrm{O}_{2}\right)$ over the ocean on the entrainment rate derived with the steady state box model runs for cases G04a (light blue) and G07a (dark blue). Lower panel: Relative error of the Lagrangian model result for $\mathrm{H}_{2} \mathrm{O}_{2}$ compared to the measurements versus the dry deposition velocity.

for the nighttime dry deposition above a forest canopy in Michigan. These studies show that there is an uncertainty of probably one order of magnitude, and the model results are within the range of the measurements. Other possibilities to bring the values derived from the $\mathrm{CO}$ and $\mathrm{HCHO}$ analyses closer would be possible heterogeneous loss processes of $\mathrm{HCHO}$ on aerosol particles or the overprediction of $\mathrm{HCHO}$ formation in our chemistry scheme.

The $E R$ values derived in the present study may be compared with results of previous studies. From hydrocarbon measurements, Dillon et al. (2002) derived entrainment rates of the urban pollution plumes of Sacramento, Toronto and Nashville of $(0.23 \pm 0.09) \mathrm{h}^{-1}, 0.1 \mathrm{~h}^{-1}$ and $0.20-0.22 \mathrm{~h}^{-1}$ respectively, similar to our $24 \mathrm{~h}$ average. A trajectory model indicated a slightly higher $E R$ of $0.3-0.5 \mathrm{~h}^{-1}$ for the first plume. A much smaller value of $(0.010 \pm 0.004) \mathrm{h}^{-1}$ was found for rapid long range transport by Price et al. (2004) using different methods (trajectory calculations, trace gas and aerosol observations). This can be rationalised by the much more important role fast turbulent mixing and convection play in the BL compared to the FT, where less turbulent horizontal transport usually dominates. 


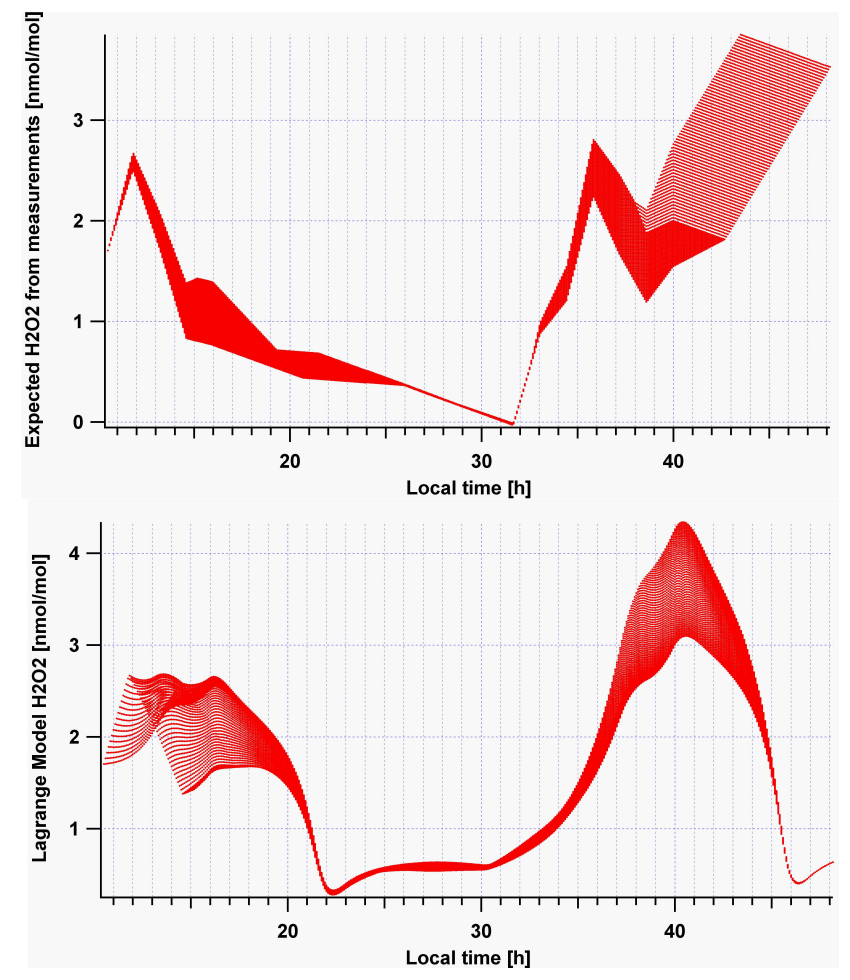

Fig. 11. Upper panel: Expected $\mathrm{H}_{2} \mathrm{O}_{2}$ mixing ratios along the 57 different trajectories prescribed by the varying $k$ values. The variation of the mixing ratio as a function of local time arises from the measured longitudinal gradient, the effect of the different starting times of the trajectories and the superimposed diurnal cycle. Lower panel: $\mathrm{H}_{2} \mathrm{O}_{2}$ mixing ratios calculated along the 57 different trajectories with the box model (Lagrangian mode, reference run).

\section{3 $\quad \mathrm{H}_{2} \mathrm{O}_{2}$ dry deposition velocities over ocean and land}

\subsubsection{Ocean}

The average dry deposition velocity $v_{d}\left(\mathrm{H}_{2} \mathrm{O}_{2}\right)$ over the ocean has been assessed using the steady state model. $v_{d}$ was varied such that measured and modelled hydrogen peroxide match. Entrainment was included in the model with a constant rate $E R=0.12 \mathrm{~h}^{-1}$. The initial and boundary conditions were taken from case G04a and G07a (eastern sector) with mean mixing ratios in the FT of $\approx 4.3 \mathrm{nmol} / \mathrm{mol}$ and $\approx 1.0 \mathrm{nmol} / \mathrm{mol}$, respectively $\left(51.5-52.5^{\circ} \mathrm{W}, \mathrm{G} 04\right.$ and G07). The latter mixing ratio was deduced from the total peroxides as described in Sect. 3.3. This corresponds to "positive" (concentrating) entrainment in the first and "negative" (diluting) entrainment in the second case. An optimum match was obtained with deposition velocities of $v_{d}\left(\mathrm{H}_{2} \mathrm{O}_{2}\right) \approx 1.4 \mathrm{~cm} / \mathrm{s}$ and $v_{d}\left(\mathrm{H}_{2} \mathrm{O}_{2}\right) \approx 1.3 \mathrm{~cm} / \mathrm{s}$ for $\mathrm{G} 04 \mathrm{a}$ and $\mathrm{G} 07 \mathrm{a}$, respectively.

The sensitivity towards the entrainment rate (see upper panel of Fig. 10) was tested by first changing the latter to the smaller value from the CO calculations of $\approx 0.01 \mathrm{~h}^{-1}$. This gives deposition velocities of $<0.1 \mathrm{~cm} / \mathrm{s}$ and $>1.8 \mathrm{~cm} / \mathrm{s}$, respectively, for the two cases. A deposition velocity of $<0.1 \mathrm{~cm} / \mathrm{s}$ over the ocean appears very small compared to values found in the literature (see Sect. 4.3.3) and computed with the 1-D SCM. In addition, the lower entrainment rate implies an inconsistency between the deposition velocities derived from the two cases. The deposition velocities over the ocean are expected to be similar because the BL height is the same and constant in both cases, unlike the BL over the rainforest. On the other hand, setting $E R$ to the high value of $\approx 0.69 \mathrm{~h}^{-1}$ results in unrealistically high $v_{d}>10 \mathrm{~cm} / \mathrm{s}$ and $v_{d}>4 \mathrm{~cm} / \mathrm{s}$ indicating that this value can only be an upper estimate for the diurnal mean entrainment rate. Both provide an indication of the magnitude of $0.12 \mathrm{~h}^{-1}$ for the mean entrainment rate being correct. It should be noted, however, that an average value of $1.35 \mathrm{~cm} / \mathrm{s}$ for the dry deposition velocity over the ocean seems to be quite large for rather constant windspeeds of about $6 \mathrm{~m} / \mathrm{s}$. The latter result in a maximum dry deposition velocity of $\approx 0.5 \mathrm{~cm} / \mathrm{s}$ in the 1 -D SCM considering neutral conditions and the dependency of the windspeed on the ocean surface roughness.

\subsubsection{Rainforest}

From the Lagrangian model an estimate of the dry deposition velocity over the rainforest has been deduced, again by matching interpolated measurements at $55.86^{\circ} \mathrm{W}$ and model results after $24 \mathrm{~h}$ transport time. $\mathrm{H}_{2} \mathrm{O}_{2}$ was the only (measured) species freely calculated in the model. The median mixing ratio in the $\mathrm{BL}$ of the pure oceanic bin was taken as a starting value, and entrainment was included with the parameter $E R$ set to the same value as in Sect. 4.3.1. Additionally, mean hydrogen peroxide mixing ratios for the FT of all longitudinal bins were calculated and accordingly interpolated so that a longitude dependent difference of the $\mathrm{H}_{2} \mathrm{O}_{2}$ mixing ratio between the $\mathrm{BL}$ and the FT was available for the longitude range examined. The dry deposition velocity was set to $1.35 \mathrm{~cm} / \mathrm{s}$ over the ocean, the mean value derived in Sect. 4.3.1.

An unchanged and constant value of $1.35 \mathrm{~cm} / \mathrm{s}$ over the rainforest leads to an almost perfect agreement of model and measurements after $24 \mathrm{~h}$ transport time, while a value of $0.5 \mathrm{~cm} / \mathrm{s}$ produces an overestimation of $\approx 14 \%$, and a value of $2.0 \mathrm{~cm} / \mathrm{s}$ an underestimation of $\approx 8 \%$ (lower panel of Fig. 10). The latter is probably not significant considering the accuracy of $\approx 15 \%$ at $300 \mathrm{pmol} / \mathrm{mol}$ of the hydrogen peroxide measurements. The relatively strong diurnal cycle of $\mathrm{H}_{2} \mathrm{O}_{2}$ in the measurements and the Lagrangian model results, reflecting the quite short overall lifetime of this compound in the examined environment, constitutes a further uncertainty in the estimate (see Fig. 11).

\subsubsection{Comparison with results from other studies}

The present study suggests a best estimate for the $24 \mathrm{~h}$ mean of the dry deposition velocity of hydrogen peroxide of 
Table 6. $\mathrm{H}_{2} \mathrm{O}_{2}$ dry deposition velocities $v_{d}\left(\mathrm{H}_{2} \mathrm{O}_{2}\right)$ and respective $\mathrm{BL}$ deposition rates found over land and over sea surfaces in different studies. $v_{d, l}\left(\mathrm{H}_{2} \mathrm{O}_{2}\right)$ : dry deposition velocity over land, $v_{d, s}\left(\mathrm{H}_{2} \mathrm{O}_{2}\right)$ : dry deposition velocity over the sea. For detailed information and discussion of the different results see text.

\begin{tabular}{|c|c|c|c|c|}
\hline Reference & $v_{d, l}\left(\mathrm{H}_{2} \mathrm{O}_{2}\right)[\mathrm{cm} / \mathrm{s}]$ & $v_{d, s}\left(\mathrm{H}_{2} \mathrm{O}_{2}\right)[\mathrm{cm} / \mathrm{s}]$ & Deposition rate $\left[\mathrm{s}^{-1}\right]$ & Region \\
\hline Walcek (1987) & 1 & & & NE United States \\
\hline Baer and Nester (1992) & 1.5 & & & $\begin{array}{l}\text { Upper Rhine Valley } \\
\text { (Germany) }\end{array}$ \\
\hline Gao et al. (1993) & 2.5 & & & above forest \\
\hline Heikes et al. (1996) & & 0.88 & $1.4 \times 10^{-5}$ & South Atlantic \\
\hline Hall and Claiborn (1997) & $1-5$ & & & coniferous forest in Canada \\
\hline Sillman et al. (1998) & $\approx 5$ & & & Tennessee \\
\hline Junkermann and Stockwell (1999) & & & $1 \times 10^{-5}$ & tropical South Atlantic \\
\hline Valverde-Canossa et al. (2006) & $(5 \pm 2)$ & & & Fichtelgebirge (Germany) \\
\hline This study & 1.35 & 1.35 & $\begin{array}{l}1.35 \times 10^{-5} \ldots 4 \text { (land) } \\
3.25 \times 10^{-5}(\text { sea })\end{array}$ & $\begin{array}{l}\text { tropical rainforest } \\
\text { tropical Atlantic }\end{array}$ \\
\hline
\end{tabular}

$1.35 \mathrm{~cm} / \mathrm{s}$ over the ocean as well as over the rainforest. With the values for the BL height of $\approx 400 \mathrm{~m}$ and $\approx 100-1000 \mathrm{~m}$ (ocean and rainforest) deposition rates of $3.25 \times 10^{-5} \mathrm{~s}^{-1}$ and $1.35 \times 10^{-5}$ up to $1.35 \times 10^{-4} \mathrm{~s}^{-1}$ are inferred.

Walcek (1987) theoretically calculated a value of $1 \mathrm{~cm} / \mathrm{s}$ for the $\mathrm{H}_{2} \mathrm{O}_{2}$ dry deposition velocity over the northeast United States which is roughly in agreement with our result for the rainforest and with the mean 1-D SCM result over land. Baer and Nester (1992) assessed an average $v_{d}\left(\mathrm{H}_{2} \mathrm{O}_{2}\right)=1.5 \mathrm{~cm} / \mathrm{s}$ for the region of the Upper Rhine Valley (Germany) in March 1985 with a regional mesoscale diffusion model, again relatively close to our estimate. Gao et al. (1993) used a coupled Diffusion-Chemistry-Model to calculate an $\mathrm{H}_{2} \mathrm{O}_{2}$ deposition velocity of $2.5 \mathrm{~cm} / \mathrm{s}$ above a forest, about twice our value. Heikes et al. (1996) deduce a deposition flux of $(4 \pm 4) \times 10^{10} \mathrm{~cm}^{-2} \mathrm{~s}^{-1}$ for $\mathrm{H}_{2} \mathrm{O}_{2}$ and $(1.1 \pm 0.5) \times 10^{10} \mathrm{~cm}^{-2} \mathrm{~s}^{-1}$ for $\mathrm{CH}_{3} \mathrm{OOH}$ from measurement data over the South Atlantic. At the given typical wind speed of $7 \mathrm{~m} / \mathrm{s}$ at $10 \mathrm{~m}$ a.s.l. this corresponds to deposition velocities of 0.88 and $0.5 \mathrm{~cm} / \mathrm{s}$, respectively, the first value for $\mathrm{H}_{2} \mathrm{O}_{2}$ being smaller than our estimate. Also the derived deposition rate of $1.4 \times 10^{-5} \mathrm{~s}^{-1}$ for $\mathrm{H}_{2} \mathrm{O}_{2}\left(6 \times 10^{-6} \mathrm{~s}^{-1}\right.$ for $\mathrm{CH}_{3} \mathrm{OOH}$ ) at a marine $\mathrm{BL}$ height of $700 \mathrm{~m}$ is rather smaller than our value. From gradient measurements (modified Bowen method) Hall and Claiborn (1997) compute diurnal maxima of $v_{d}=5 \mathrm{~cm} / \mathrm{s}$ for $\mathrm{H}_{2} \mathrm{O}_{2}$ and $1.6 \mathrm{~cm} / \mathrm{s}$ for organic peroxide as well as nocturnal values of $1 \mathrm{~cm} / \mathrm{s}$ and $0.5 \mathrm{~cm} / \mathrm{s}$, respectively, over a coniferous forest in Canada. Their results show that the surface resistance is negligible in the case of $\mathrm{H}_{2} \mathrm{O}_{2}$ and that the dry deposition of all peroxides is limited by turbulence. Sillman et al. (1998) derive a dry deposition velocity of $\approx 5 \mathrm{~cm} / \mathrm{s}$ for $\mathrm{H}_{2} \mathrm{O}_{2}$ from correlations of $\mathrm{O}_{3}, \mathrm{NO}_{\mathrm{z}}$ and peroxides during the Middle Tennessee Ozone Study (model and measurements), again significantly higher than the value found in the present study. Junker- mann and Stockwell (1999) estimate hydrogen peroxide and methyl hydroperoxide dry deposition rates of $1 \times 10^{-5} \mathrm{~s}^{-1}$ and $0.8 \times 10^{-5} \mathrm{~s}^{-1}$ above the tropical South Atlantic in October and November 1994. The value for $\mathrm{H}_{2} \mathrm{O}_{2}$ is about a third of the value deduced in the present study. However, at that time the uncertainties in chemical rate constants were still too high to make an exact estimate according to the authors. Additionally, the entrainment rate in our study could be overestimated over the ocean, as it was calculated as a $24 \mathrm{~h}$ mean value mainly over land and as the entrainment over the ocean may be smaller due to the generally higher stability towards vertical exchange.

Valverde-Canossa et al. (2006) deduced an average daytime $v_{d}\left(\mathrm{H}_{2} \mathrm{O}_{2}\right)$ of $(5 \pm 2) \mathrm{cm} / \mathrm{s}$ over a Norway spruce forest in the Fichtelgebirge (Germany) with the relaxed eddyaccumulation technique (REA), representing an upper limit for the diurnal average due to the generally less intense nighttime turbulence over land. Like the study by Hall and Claiborn (1997), their results indicate that daytime $\mathrm{H}_{2} \mathrm{O}_{2}$ dry deposition is limited by turbulence, similar to the dry deposition of $\mathrm{HNO}_{3}$, and that it can be accurately represented by the combination of an aerodynamic and a quasi-laminar boundary resistance alone. In line with these observations, $v_{d}\left(\mathrm{H}_{2} \mathrm{O}_{2}\right)$ was found to be significantly underestimated by the 1-D SCM used in the present study when applying a relatively high surface uptake resistance (Ganzeveld et al., 2006b), whereas the disagreement diminished when implementing a very small uptake resistance. Table 6 gives a synopsis of all studies including our results. To summarise, our estimate for the dry deposition velocity over the ocean is rather higher than previous estimates as well as the 1-D SCM result, probably representing an upper limit because of the relatively high entrainment rate assumed in our calculations. Our estimate of the dry deposition velocity over the rainforest, on the other hand, is within and rather at the lower end 

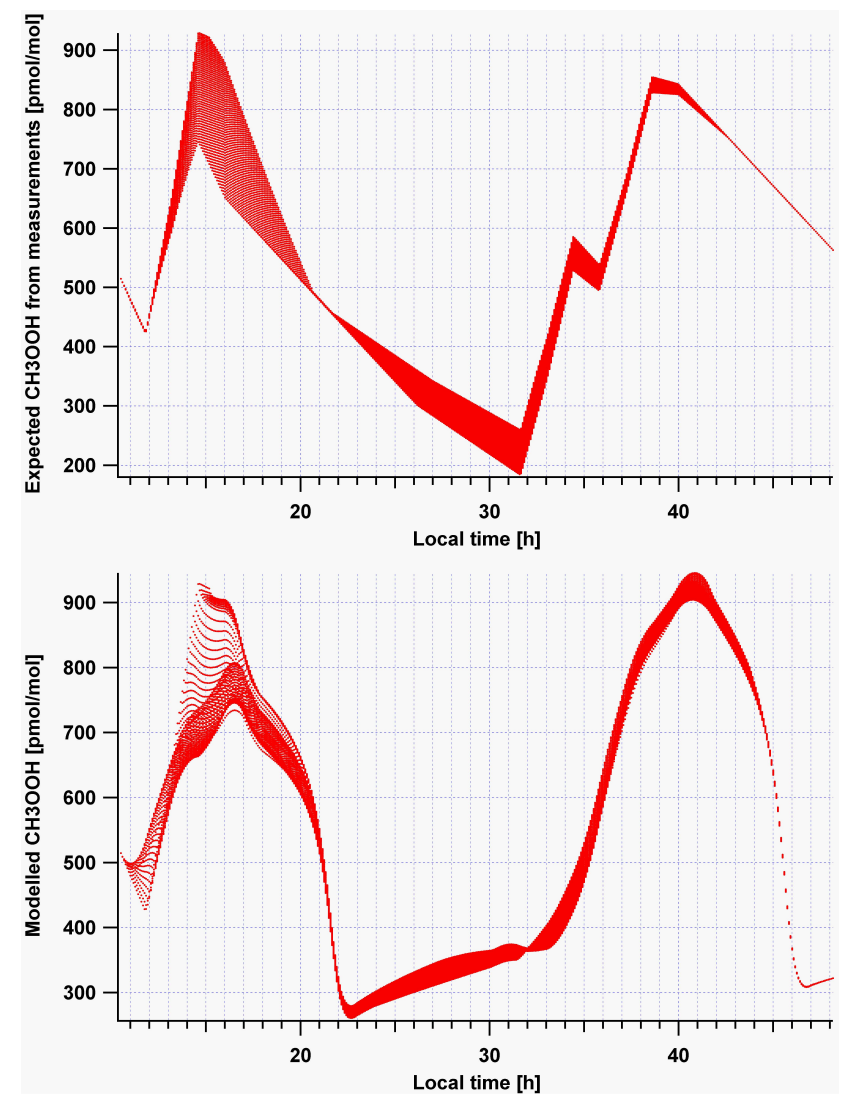

Fig. 12. Upper panel: Expected $\mathrm{CH}_{3} \mathrm{OOH}$ mixing ratios along the 57 different trajectories prescribed by the varying $k$ values. The variation of the mixing ratio as a function of local time arises from the measured longitudinal gradient, the effect of the different starting times of the trajectories and the superimposed diurnal cycle. Lower panel: $\mathrm{CH}_{3} \mathrm{OOH}$ mixing ratios calculated along the 57 different trajectories with the box model (Lagrangian mode, reference run).

of the range of results for land surfaces from other studies $(1-5 \mathrm{~cm} / \mathrm{s})$. It furthermore agrees well with the result of the 1-D SCM. It should be noted that the present study focusses on dry deposition since precipitation was absent along the studied air mass trajectories.

\subsection{Errant sources or sinks of organic peroxides}

As shown in Sect. 4.1, the measured organic peroxides show a distinct longitudinal gradient during GABRIEL, similar to $\mathrm{CO}$ and formaldehyde. To investigate if this gradient can be explained by photochemical degradation of organic precursors escaping the forest canopy, the Lagrangian model was used to calculate the change of the mixing ratio along the 57 trajectories. As in the hydrogen peroxide model run a constant entrainment rate of $0.12 \mathrm{~h}^{-1}$ from the FT was assumed, and the longitude dependent FT mixing ratios were determined. A lower dry deposition rate than for $\mathrm{H}_{2} \mathrm{O}_{2}$ was used,
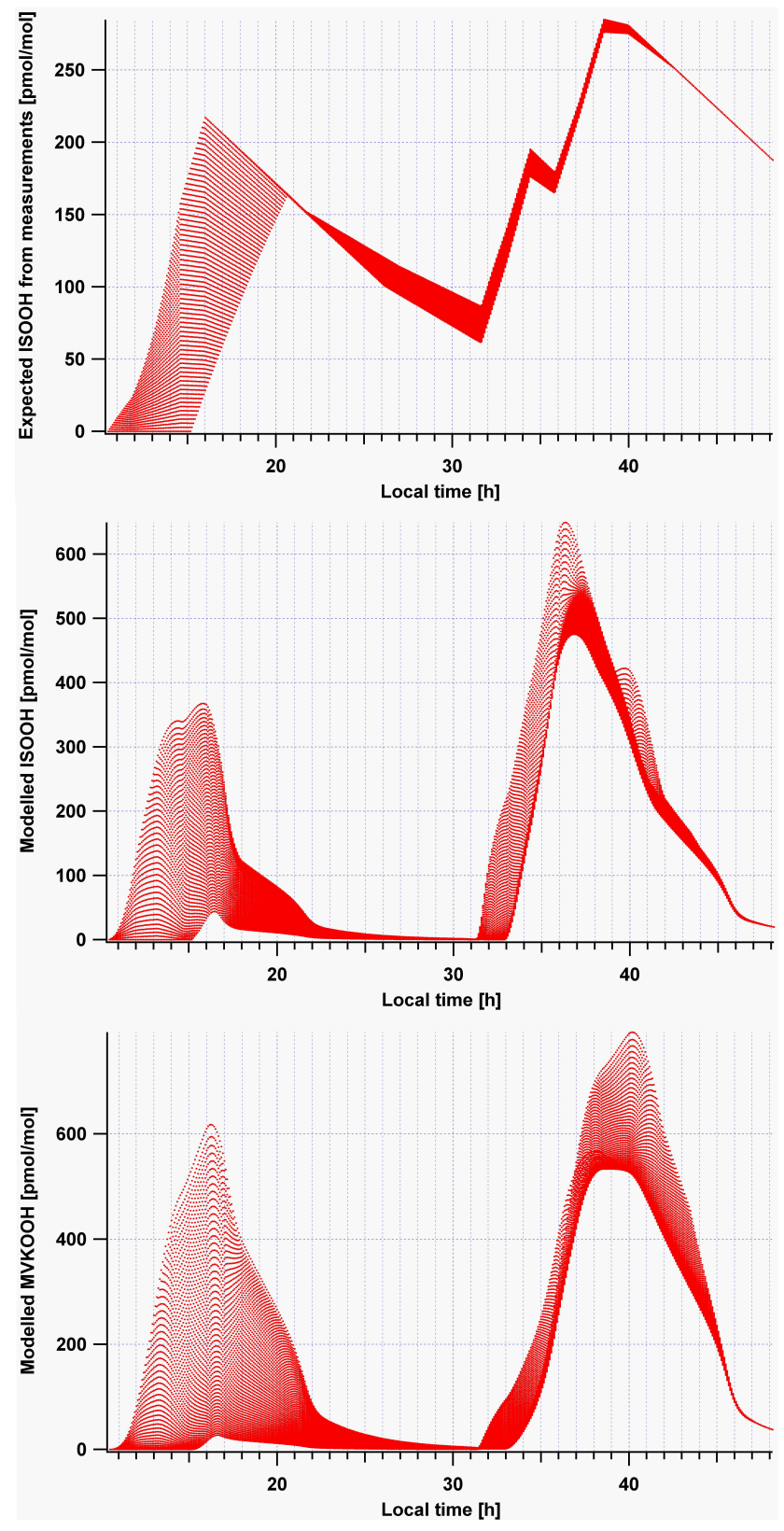

Fig. 13. Upper panel: Expected ISOOH/MVKOOH mixing ratios along the 57 different trajectories prescribed by the varying $k$ values. The variation of the mixing ratio as a function of local time arises from the measured longitudinal gradient, the effect of the different starting times of the trajectories and the superimposed diurnal cycle. Middle panel: ISOOH mixing ratios calculated along the 57 different trajectories with the box model (Lagrangian mode, reference run). Lower panel: MVKOOH mixing ratios calculated along the 57 different trajectories with the box model (Lagrangian mode, reference run).

namely $0.68 \cdot v_{d}\left(\mathrm{H}_{2} \mathrm{O}_{2}\right)=0.92 \mathrm{~cm} / \mathrm{s}$ over the ocean (average ratio $v_{d}\left(\mathrm{H}_{2} \mathrm{O}_{2}\right) / v_{d}(\mathrm{ROOH})$ from Junkermann and Stockwell (1999) and Heikes et al. (1996) above the South Atlantic) 
and $0.41 \cdot v_{d}\left(\mathrm{H}_{2} \mathrm{O}_{2}\right)=0.55 \mathrm{~cm} / \mathrm{s}$ over the land (diurnal average ratio $v_{d}\left(\mathrm{H}_{2} \mathrm{O}_{2}\right) / v_{d}(\mathrm{ROOH})$ following Hall and Claiborn, 1997). The modelled organic peroxides $\mathrm{CH}_{3} \mathrm{OOH}$, ISOOH and $\mathrm{MVKOOH}$ were initialised to their measured medians in the ocean bin, i.e. the total measured organic peroxide for $\mathrm{CH}_{3} \mathrm{OOH}$ and zero for both other peroxides. Since the organic peroxides at $1-3 \mathrm{~km}$ a.s.l. do not exhibit an increase from east to west we have assumed that they consist only of $\mathrm{CH}_{3} \mathrm{OOH}$.

Figures 12 and 13 show the results for the reference run. The model predicted diurnal cycle for $\mathrm{CH}_{3} \mathrm{OOH}$ is similar to the expected one. Maximum and minimum values are in relatively good agreement and the amplitude of the cycle also matches quite well, particularly when taking into account that the night values of the expected cycle have been deduced with the simplified approach of linear interpolation of the daytime values.

For ISOOH and MVKOOH the agreement is not so good. Especially on the second day ISOOH is obviously strongly overestimated (model peak 500-600 pmol/mol, expected $\approx 275 \mathrm{pmol} / \mathrm{mol}$ ). Also for MVKOOH a clear overestimation emerges with the measured isoprene and MVK data as input (model maximum 530-800 $\mathrm{pmol} / \mathrm{mol}$ compared to the expected $\approx 275 \mathrm{pmol} / \mathrm{mol}$ ).

The reference run results in a mean longitudinal gradient of the total organic peroxide during the $24 \mathrm{~h}$ transport time of $1.81 \mathrm{pmol} / \mathrm{mol} \mathrm{km}^{-1}$ compared to $0.94 \mathrm{pmol} / \mathrm{mol} \mathrm{km}^{-1}$ expected from the measurements.

We conclude that with the assumptions made the modelled total organic peroxide mixing ratio has to be considered inconsistent with the measurements, indicating a significantly lower mixing ratio. The formation of ISOOH from isoprene alone points at the possibility of an overestimation of isoprene by the measurements or that the chemistry is not fully understood. One alternative in explaining the discrepancy might be an effective heterogeneous loss resulting in a lifetime similar to the lifetime of the organic peroxides due to gas phase chemistry alone.

Sensitivity studies were carried out with a) an increased entrainment rate of $0.689 \mathrm{~h}^{-1}, \mathrm{~b}$ ) increased deposition velocities

$v_{d}(\mathrm{ISOOH})=v_{d}(\mathrm{MVKOOH}) \stackrel{!}{=} v_{d}\left(\mathrm{H}_{2} \mathrm{O}_{2}\right)$

and c) halved isoprene and MVK mixing ratios.

The first sensitivity run a) still produces too high mixing ratios for ISOOH and MVKOOH (diurnal cycle maxima of $350-500 \mathrm{pmol} / \mathrm{mol}$ for ISOOH and $250-350 \mathrm{pmol} / \mathrm{mol}$ for $\mathrm{MVKOOH}$ ), obviously due to the short chemical lifetime of these compounds in the model. Furthermore, the $\mathrm{CH}_{3} \mathrm{OOH}$ simulated and expected diurnal cycles do not match as well anymore, and the low morning minimum is overestimated because of a positive nighttime entrainment.

The second run b) results again in far too high concentrations, whereby the modelled diurnal cycle of $\mathrm{CH}_{3} \mathrm{OOH}$ fits even better to the expected one during daylight than in the reference run. Even a further increase of the deposition velocity for ISOOH and MVKOOH to a value of $5 \mathrm{~cm} / \mathrm{s}$, significantly higher than the value derived for $\mathrm{H}_{2} \mathrm{O}_{2}$, still produces much too high values (maxima on the second day of 450$600 \mathrm{pmol} / \mathrm{mol}$ and $425-550 \mathrm{pmol} / \mathrm{mol}$, respectively).

With the third run c) we obtain a much better agreement of modelled and expected ISOOH and MVKOOH, while there is still a tendency to overestimate the relatively longer-lived MVKOOH.

The sensitivity tests corroborate the possibility that either isoprene and MVK are overestimated by the measurements, the isoprene chemistry is not completely understood or the organic peroxides are subject to more efficient loss than accounted for in the model. This may affect either the radical precursor species $\mathrm{RO}_{\mathrm{x}}$, as described in de Reus et al. (2005), or the peroxides themselves. Potential model deficiencies include heterogeneous loss, missing reaction pathways involving $\mathrm{RO}_{\mathrm{x}}$, or underestimated photolysis rates of peroxides (Matthews et al., 2005). Too high isoprene and MVK would fit to the overestimation of $\mathrm{HCHO}$ in the Lagrange as well as the steady state model over land, while a higher dry deposition alone cannot alleviate the discrepancy over the sea. Regarding the representation of isoprene chemistry in the used chemical mechanism some authors have reported that there can be a strong dependency of the product yields of isoprene oxidation on the complexity of the applied condensed mechanism (Paulson and Seinfeld, 1992; Barket et al., 2004; Fan and Zhang, 2004). Pöschl et al. (2000) conclude that a box model with the condensed Mainz Isoprene Mechanism (MIM) included also in MECCA v0.1p produces rather lower organic peroxide mixing ratios under tropical low $\mathrm{NO}_{\mathrm{x}}$ conditions compared to the extended Master Chemical Mechanism (MCM). Nevertheless, the differences between MIM and MCM results were mostly found to be less than $10-20 \%$ for key chemical species including $\mathrm{CH}_{3} \mathrm{OOH}$ throughout the test scenarios. The deviations in that study could be assigned mainly to a different representation of organic nitrate chemistry. von Kuhlmann et al. (2004) confirm that this is in principle also valid for the 3-D CTM MATCHMPIC.

Thornton et al. (2002), on the other hand, found that a too high yield of the branching ratio and the rate constant for organic peroxide formation via $\mathrm{RO}_{2}+\mathrm{HO}_{2}$ was responsible for discrepancies found between model-predicted and measured ozone production rates. In addition, Hasson et al. (2004) suggested the formation of other products than peroxides including $\mathrm{OH}$ from the reaction of $\mathrm{CH}_{3} \mathrm{C}(\mathrm{O}) \mathrm{O}_{2}+\mathrm{HO}_{2}$. Their suggestion has recently been confirmed in laboratory kinetics measurements, and the respective reaction of the peroxy radical of MVK with $\mathrm{HO}_{2}$ is expected to follow a similar reaction path (J. Crowley and co-workers, private communication). To estimate possible effects on the organic peroxides, 


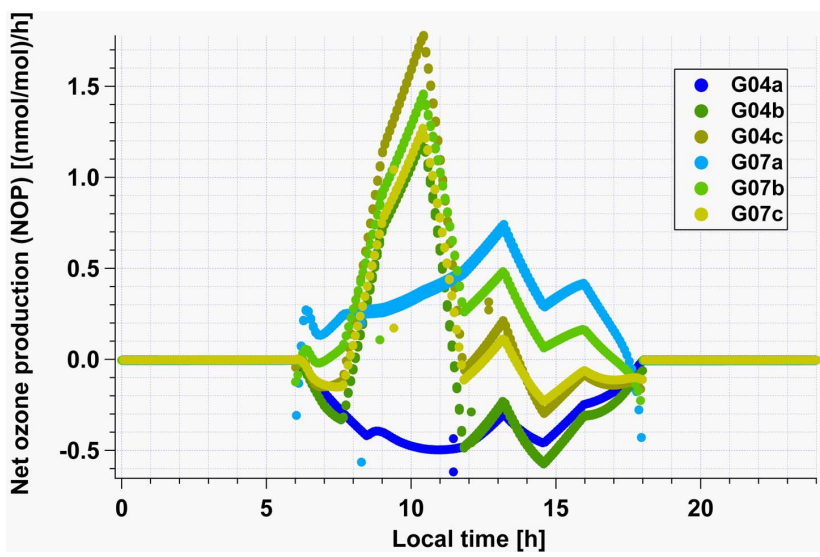

Fig. 14. Net ozone production calculated with the steady state box model for the 6 cases defined in Sect. 3.3.

the reaction

$\mathrm{MVKO}_{2}+\mathrm{HO}_{2} \rightarrow \mathrm{MVKOOH}+\mathrm{O}_{2}$

in the MECCA chemical mechanism has been substituted by an analogon of the reaction of $\mathrm{MVKO}_{2}$ with $\mathrm{NO}$

$\mathrm{MVKO}_{2}+\mathrm{HO}_{2} \rightarrow 0.5 \mathrm{MVKOOH}+0.5 \mathrm{OH}$

$+0.125 \mathrm{CH}_{3} \mathrm{C}(\mathrm{O}) \mathrm{O}_{2}+0.125 \mathrm{HOCH}_{2} \mathrm{C}(\mathrm{O}) \mathrm{CH}_{3}$

$+0.375 \mathrm{HCHO}+0.125 \mathrm{CO}+0.375 \mathrm{HO}_{2}$

$+0.25 \mathrm{CH}_{3} \mathrm{C}(\mathrm{O}) \mathrm{CHO}$

with the reaction rate unchanged compared to Reaction (R1). The implementation leads to a reduced difference of only $179 \mathrm{pmol} / \mathrm{mol}$ between modelled and expected total organic peroxide after $24 \mathrm{~h}$ transport time, compared to $371 \mathrm{pmol} / \mathrm{mol}$ with the original mechanism. This is mainly due to a significantly lower predicted $\mathrm{MVKOOH}$ mixing ratio.

Taking into account all available information discussed up to this point, either a modified chemical mechanism like the one proposed above, leading to a reduction of the organic peroxide production, or heterogeneous loss help explain the lower than predicted organic peroxide mixing ratio, particularly since the short chemical lifetime of ISOOH and MVKOOH makes these compounds weakly sensitive or almost insensitive towards changes in $E R$ and $v_{d}$.

\subsection{Net BL ozone production}

The net ozone production (NOP) in the BL above the ocean and the rainforest was calculated using the steady state model. The last day of a series of 7 days total runtime was chosen to represent steady state. After that period all important species were found to be in dynamic equilibrium. $\mathrm{Cl}$ chemistry was included and the time resolution of the output decreased to $5 \mathrm{~min}$. Figure 14 displays the results for the 6 cases G04a to G07c.
For case G04a ozone destruction prevails during the entire day with a maximum rate of $\approx 0.5 \mathrm{nmol} / \mathrm{mol} \mathrm{h}^{-1}$. The integrated NOP for daylight hours is $-4 \mathrm{nmol} / \mathrm{mol}$. Case G04b shows $\mathrm{O}_{3}$ destruction between sunrise and about 08:00 LT with a maximum rate of $\approx 0.325 \mathrm{nmol} / \mathrm{mol} \mathrm{h}^{-1}$ followed by a significant NOP rise up to $1.25 \mathrm{nmol} / \mathrm{mol} \mathrm{h}^{-1}$ (coincident with the NO peak at $\approx 10: 25 \mathrm{LT}$ ). Subsequently the NOP decreases again to negative values from $\approx 11: 25 \mathrm{LT}$ onward. The integrated $\mathrm{O}_{3}$ production is $-0.29 \mathrm{nmol} / \mathrm{mol}$. Case $\mathrm{G} 04 \mathrm{c}$ exhibits a similar evolution as case G04b but shifted to higher values in the region of destruction, leading to a positive integrated NOP of $+3.33 \mathrm{nmol} / \mathrm{mol}$. In contrast to case G04a case G07a is characterised by ozone production rather than ozone destruction, due to the higher NO mixing ratios in the second case (integrated NOP $+4.4 \mathrm{nmol} / \mathrm{mol}$ ). While the median NO mixing ratio is $5 \mathrm{pmol} / \mathrm{mol}$ at the time of the measurement (14:45-15:00 LT) for case G04a, it is $19 \mathrm{pmol} / \mathrm{mol}$ (11:30-11:45 LT) for case G07a. This results in a difference of almost $20 \mathrm{pmol} / \mathrm{mol}$ at a fixed local time in the expected diurnal cycles for both flight segments. Finally, cases G07b and G07c (integrated NOP +4.69 and $+2.03 \mathrm{nmol} / \mathrm{mol}$ ) resemble again case G04b.

Thus it appears that minor ozone production as well as destruction are in principle possible in the BL over the Atlantic Ocean northeast of the Guyanas, depending on the particular NO mixing ratio on a certain day. Nevertheless the assumption in case $\mathrm{G} 07 \mathrm{a}$ of an $\mathrm{NO}$ mixing ratio rising from $19 \mathrm{pmol} / \mathrm{mol}$ in the morning up to almost $30 \mathrm{pmol} / \mathrm{mol}$ around noon appears rather improbable. The measurements on the respective flight leg may potentially have been influenced by upwind emissions from ships. Altogether, a tendency for ozone destruction is expected in the unpolluted air.

The second result is that in the BL above the rainforest a tendency for ozone production is observed. In all land cases except G04b the integrated NOP is positive during daytime depending on the actual height of the diurnal cycle NO peak. In turn, the measured median NO mixing ratios are smaller during flight G04 than during flight G07. The NOP in all 6 cases closely follows the NO diurnal cycle. The calculated average chemical tendency of $+2.44 \mathrm{nmol} / \mathrm{mol} \mathrm{d}^{-1}$ over land for the two flights is even smaller than the observed increase of the BL median mixing ratio of ozone from the morning to the evening for all flights of roughly $5 \mathrm{nmol} / \mathrm{mol}$, although it does not yet compensate for the effect of dry deposition of ozone. Also the longitudinal gradient with an increase from east to west (Fig. 3) fits nicely to the positive NOP. This is again in line with the finding that mixing-in of FT air into the BL, especially during the daytime, is an important process in defining the mixing ratio of medium- up to longerlived compounds in the BL over the tropical rainforest, since the ozone mixing ratios in the layer between $1-3 \mathrm{~km}$ altitude $(20-50 \mathrm{nmol} / \mathrm{mol})$ are significantly higher than in the BL with local maxima at $2-3.5 \mathrm{~km}$, similar to $\mathrm{CO}$. The finding of net ozone production over the remote rainforest region of the Guyanas in the long dry season (August to November) 
differs from the ozone destruction of $5 \% / \mathrm{h}$ during daytime reported for the same region from measurements at two ground based stations in Suriname in the short dry season (February and March) during LBA-CLAIRE98 (Quesada et al., 2001). The overall destruction of ozone was explained with a combination of very low photochemical production and strong dry deposition.

As can be anticipated from the diurnal cycle of the NOP following closely the NO mixing ratio, a strong positive correlation is found between these two variables in the steady state box model (Fig. 15). It can also be seen that a higher radiation intensity results in a steeper slope of the correlation.

\section{Conclusions}

Significant longitudinal gradients with an increase from east to west were found for $\mathrm{CO}, \mathrm{O}_{3}, \mathrm{HCHO}$ and organic peroxide mixing ratios in the $\mathrm{BL}$ over the tropical Atlantic Ocean and the Guyanas during GABRIEL. The gradient of $\mathrm{CO}$ derived from the longitude dependent medians is about twice as high $\left(54 \mathrm{pmol} / \mathrm{mol} \mathrm{km}^{-1}\right)$ as during LBACLAIRE98. By analysing single flights we find $\mathrm{CO}$ gradients of $16-48 \mathrm{pmol} / \mathrm{mol} \mathrm{km}^{-1}$, and a gradient of $17.5 \mathrm{pmol} / \mathrm{mol}$ $\mathrm{km}^{-1}$ has been obtained from a "quasi Lagrangian" case identified in the measurement data.

A Lagrangian box model clearly underestimates this $\mathrm{CO}$ gradient $\left(5.6 \mathrm{pmol} / \mathrm{mol} \mathrm{km}^{-1}\right)$. Provided the chemistry is represented correctly in the model this implies that there must be other sources of $\mathrm{CO}$ in the BL. A sensitivity study suggests that the model-measurement discrepancies cannot be explained by measurement errors alone. Three processes potentially influencing the carbon monoxide mixing ratio in the BL were examined: biomass burning, emissions from soil and vegetation and entrainment from the FT. According to this study biomass burning in parts of Africa and/or eastern Brazil can explain the relatively high $\mathrm{CO}$ found during several flights at an altitude of $2-3 \mathrm{~km}$ a.s.l. No indication was found for an important influence of local biomass burning. An upper estimate of the effect of soil and plant emissions showed that these, together with photochemistry, can probably still not account for the full range of observed $\mathrm{CO}$ gradients. Nonetheless they can significantly contribute to the $\mathrm{CO}$ budget in the $\mathrm{BL}$ and even regionally outbalance the photochemical production. An upper limit estimate for the $24 \mathrm{~h}$ mean entrainment rate from the FT into the BL of $E R=0.12 \mathrm{~h}^{-1}$ was derived from the horizontal gradient and the BL-FT difference of the mixing ratio of $\mathrm{CO}$, leading to a better agreement of model and measurements.

A steady state and a Lagrangian model for $\mathrm{HCHO}$ were used to cross-check the results obtained from the $\mathrm{CO}$ analysis. The dry deposition velocity was adopted from a 1-D SCM. The model runs in both cases showed a significant overestimation of the HCHO mixing ratio. A deficiency of the chemical mechanism or an underestimation of pre-

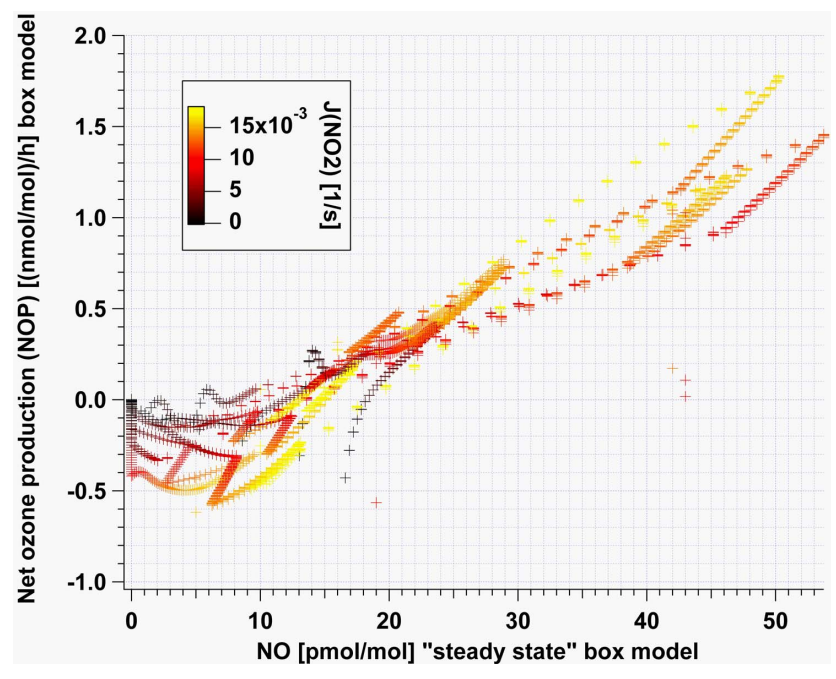

Fig. 15. Correlation between the net ozone production (NOP) and the NO mixing ratio in the "steady state" box model, colourcoded depending on the value of $J\left(\mathrm{NO}_{2}\right)$.

cursors is precluded, at least for all compounds being oxidised via formaldehyde to form $\mathrm{CO}$. An underestimation of the entrainment and perhaps of the dry deposition velocity were found to be the most likely reasons for the differences. From the two models lower limits for the maximum daytime entrainment rate of $\max \left(E R_{\text {daytime }}\right)>0.55 \mathrm{~h}^{-1}$ and $\max \left(E R_{\text {daytime }}\right)>0.69 \mathrm{~h}^{-1}$ have been calculated, implying an efficient mixing-in of FT air into the BL during daylight. The estimate would become smaller with a more efficient dry deposition though.

An $\mathrm{H}_{2} \mathrm{O}_{2}$ dry deposition velocity of $1.35 \mathrm{~cm} / \mathrm{s}$ over the ocean as well as the rainforest has been calculated with the box model assuming an entrainment rate $E R=0.12 \mathrm{~h}^{-1}$. Sensitivity tests with a changed entrainment rate further support the correctness of the estimated $24 \mathrm{~h}$ average entrainment rate. A comparison of our results with results of other studies reveals that the dry deposition velocity over the ocean is rather larger than previously derived, representing an upper limit because of the applied relatively high entrainment rate. Over the rainforest our value is within the range of previous estimates $(1-5 \mathrm{~cm} / \mathrm{s})$ and rather at the low end. Additionally, it agrees well with the explicitly computed 1-D SCM values.

The Lagrangian box model has furthermore been applied to simulate the organic peroxide longitudinal gradient assuming they only consist of methyl hydroperoxide and peroxides from isoprene and MVK oxidation. This simulation shows a significant overestimation of the organic peroxide production in the model. Further analysis leads to the conclusion that either heterogeneous loss of organic peroxides and/or their radical precursors on aerosol particles, a modified reaction of $\mathrm{HO}_{2}$ with $\mathrm{MVKO}_{2}$ in the chemical mechanism, or underestimated photodissociation of organic peroxides may explain the discrepancies. It therefore seems that improvements 
of the representation of isoprene-product chemistry in the model are needed.

Finally, the net ozone production (NOP) has been calculated with the steady state model. The results indicate that over the tropical Atlantic Ocean ozone destruction rather than production prevails. Over the rainforest ozone production with a mean rate of approximately $2.4 \mathrm{nmol} / \mathrm{mol} \mathrm{d}^{-1}$ was found. The positive NOP over the rainforest in the long dry season contrasts with results for the short dry season in the same region during LBA-CLAIRE98.

\section{Appendix A}

\section{Abbreviations and acronyms}

\begin{tabular}{|c|c|}
\hline ABLE & $\begin{array}{l}\text { Atmospheric Boundary Layer } \\
\text { Experiment }\end{array}$ \\
\hline BL & boundary layer \\
\hline $\mathbf{C C F}$ & cloud correction factor \\
\hline CMDL & $\begin{array}{l}\text { Climate Monitoring } \\
\text { Diagnostics Laboratory }\end{array}$ \\
\hline $\begin{array}{l}\text { CTM } \\
\text { DL }\end{array}$ & $\begin{array}{l}\text { Chemistry Transport Model } \\
\text { detection limit }\end{array}$ \\
\hline ЕСНАМ & $\begin{array}{l}\text { ECMWF inspirated, in Hamburg } \\
\text { enhanced climate model }\end{array}$ \\
\hline ESRL & Earth System Research Laboratory \\
\hline FT & free troposphere \\
\hline GABRIEL & $\begin{array}{l}\text { Guyanas Atmosphere-Biosphere } \\
\text { exchange and Radicals Intensive } \\
\text { Experiment with the Learjet }\end{array}$ \\
\hline GC-FID & $\begin{array}{l}\text { Gas Chromatography-Flame } \\
\text { Ionisation Detection }\end{array}$ \\
\hline GFD & $\begin{array}{l}\text { Gesellschaft } \\
\text { Flugzieldarstellung }\end{array}$ \\
\hline $\begin{array}{l}\text { GTE } \\
\text { ISON } \\
\text { ISOOH }\end{array}$ & $\begin{array}{l}\text { Global Tropospheric Experiment } \\
\text { nitrates from isoprene oxidation } \\
\text { peroxides from isoprene oxidation }\end{array}$ \\
\hline LBA-CLAIRE & $\begin{array}{l}\text { Large-Scale } \\
\text { Atmosphere Exchange Experi- } \\
\text { ment-Cooperative LBA Airborne } \\
\text { Regional Experiment }\end{array}$ \\
\hline LIF & Laser Induced Fluorescence \\
\hline LT & local time \\
\hline МАТСН-MPIC & $\begin{array}{l}\text { Model of Atmospheric Transport } \\
\text { and Chemistry - Max Planck } \\
\text { Institute for Chemistry version }\end{array}$ \\
\hline МСM & Master Chemical Mechanism \\
\hline MECCA & $\begin{array}{l}\text { Module Efficiently Calculating the } \\
\text { Chemistry of the Atmosphere }\end{array}$ \\
\hline
\end{tabular}

\begin{tabular}{|c|c|}
\hline MEK & methyl ethyl ketone \\
\hline МЕКООН & peroxides from MEK oxidation \\
\hline MIM & Mainz Isoprene Mechanism \\
\hline MODIS & $\begin{array}{l}\text { Moderate Resolution Imaging } \\
\text { Spectroradiometer }\end{array}$ \\
\hline MPAN & peroxyacryloyl nitrate \\
\hline MVK & methyl vinyl ketone \\
\hline MVКООН & peroxides from MVK oxidation \\
\hline NACA & nitrooxy acetaldehyde \\
\hline NMOC & non-methane organic compound \\
\hline NOP & net ozone production \\
\hline ONIT & $\begin{array}{l}\text { organic nitrate from higher alkyl ni- } \\
\text { trates and } \mathrm{C}_{3} \mathrm{H}_{6}+\mathrm{NO}_{3}\end{array}$ \\
\hline PAN & peroxyacetyl nitrate \\
\hline PTR-MS & $\begin{array}{l}\text { Proton Transfer Reaction-Mass } \\
\text { Spectrometer }\end{array}$ \\
\hline SCM & Single Column Model \\
\hline TDLAS & $\begin{array}{l}\text { Tunable Diode Laser Absorption } \\
\text { Spectrometer }\end{array}$ \\
\hline TUV & $\begin{array}{l}\text { Tropospheric Ultraviolet-Visible } \\
\text { Model }\end{array}$ \\
\hline VOC & volatile organic compound \\
\hline
\end{tabular}

Appendix B

Sensitivity study for the chemical production of CO

A large number of parameters was changed with the reference run generally being the starting point for the variation of the parameters. The only exception is the variation of organic peroxides. To determine the sensitivity of $\mathrm{CO}$ towards the latter, a reference run without organic peroxides was performed. Table B1 shows the results of the Lagrangian model calculations.

These results suggest a high sensitivity of $\mathrm{CO}$ mixing ratios towards $\mathrm{NO}_{3}, \mathrm{NO}, \mathrm{HCHO}, \mathrm{MVK}, \mathrm{MVKOOH}$ and nitrooxy acetaldehyde. Absolute sensitivities $[(\mathrm{nmol} / \mathrm{mol}) /(\mathrm{nmol} / \mathrm{mol})]$ towards peroxides from acetone, butane, ethane, MEK and towards nitrates from the isoprene oxidation, propene, acetaldehyde, hydroxy hydroperoxides from propene, hydroxy acetone, isoprene, MEK, organic nitrates from higher alkyl nitrates (plus $\mathrm{C}_{3} \mathrm{H}_{6}+\mathrm{NO}_{3}$ ) and ethene are intermediate, while the calculated sensitivities towards methyl hydroperoxide, acetic acid, nitric acid, nitrate from propane, peroxide from isoprene and from propane oxidation are small. For formic acid no sensitivity run was necessary due to the fact that this species is only important for $\mathrm{HO}_{\mathrm{x}}$ partitioning in the model which is prescribed by the measurements.

The upper bound of $5 \mathrm{nmol} / \mathrm{mol}$ used in the sensitivity run of $\mathrm{CH}_{3} \mathrm{C}(\mathrm{O}) \mathrm{OH}$ was chosen considering that Helas et al. (1992) reported up to $3-4 \mathrm{nmol} / \mathrm{mol}$ measured in northern Congo. For $\mathrm{CH}_{3} \mathrm{CHO}$ an upper limit of $5 \mathrm{nmol} / \mathrm{mol}$ was estimated from ranges of $1-18 \mathrm{nmol} / \mathrm{mol}$ in urban, 
Table B1. Sensitivities of CO to different chemical species; ${ }^{1}$ during nighttime only, ${ }^{2}$ diurnal average, ${ }^{3}$ constant value, ${ }^{4}$ nitrooxy acetaldehyde, ${ }^{5}$ organic nitrate from the isoprene oxidation, ${ }^{6}$ methyl ethyl ketone, ${ }^{7}$ organic nitrate from higher alkyl nitrates and $\mathrm{C}_{3} \mathrm{H}_{6}+\mathrm{NO}_{3},{ }^{8} \mathrm{i}$-propyl nitrate.

\begin{tabular}{|c|c|c|c|}
\hline Parameter & Variation Parameter [nmol/mol] & Variation CO $[\mathrm{nmol} / \mathrm{mol}]$ & Sensitivity $[(\mathrm{nmol} / \mathrm{mol}) /(\mathrm{nmol} / \mathrm{mol})]$ \\
\hline $\mathrm{NO}_{3}$ & $+0.01^{1}$ & -0.4517 & -45.17 \\
\hline NO & $+0.0024^{2}$ & +0.0666 & 27.75 \\
\hline $\mathrm{HCHO}$ & $+0.3805^{2}$ & +2.6285 & 6.908 \\
\hline MVK & $+0.258^{2}$ & +0.9933 & 3.85 \\
\hline MVKOOH & $+0.865^{2}$ & +2.7046 & 3.124 \\
\hline $\mathrm{NACA}^{4}$ & $+0.5^{3}$ & +1.1302 & 2.2604 \\
\hline $\mathrm{CH}_{3} \mathrm{C}(\mathrm{O}) \mathrm{CH}_{2} \mathrm{OOH}$ & $+0.865^{2}$ & +0.7978 & 0.922 \\
\hline ISON $^{5}$ & $+0.5^{3}$ & +0.3849 & 0.7698 \\
\hline $\mathrm{C}_{3} \mathrm{H}_{6}$ & $+0.336^{3}$ & +0.2219 & 0.6604 \\
\hline $\mathrm{CH}_{3} \mathrm{CHO}$ & $+4.845^{3}$ & +3.1208 & 0.644 \\
\hline $\mathrm{C}_{3} \mathrm{H}_{6}(\mathrm{OH}) \mathrm{OOH}$ & $+0.865^{2}$ & +0.4797 & 0.555 \\
\hline $\mathrm{CH}_{3} \mathrm{C}(\mathrm{O}) \mathrm{CH}_{2} \mathrm{OH}$ & $-0.550^{3}$ & -0.2923 & 0.531 \\
\hline isoprene & $+0.478^{2}$ & +0.2328 & 0.487 \\
\hline $\mathrm{C}_{4} \mathrm{H}_{9} \mathrm{OOH}$ & $+0.865^{2}$ & +0.3704 & 0.428 \\
\hline $\mathrm{C}_{2} \mathrm{H}_{5} \mathrm{OOH}$ & $+0.865^{2}$ & +0.3459 & 0.400 \\
\hline MEK $^{6}$ & $+1.798^{3}$ & +0.5379 & 0.299 \\
\hline МЕКОOH & $+0.865^{2}$ & +0.2433 & 0.281 \\
\hline $\mathrm{ONIT}^{7}$ & $+0.05^{3}$ & +0.01 & 0.14 \\
\hline $\mathrm{C}_{2} \mathrm{H}_{4}$ & $+2.6^{3}$ & +0.2658 & 0.1022 \\
\hline $\mathrm{CH}_{3} \mathrm{OOH}$ & $+0.865^{2}$ & +0.0775 & 0.0896 \\
\hline $\mathrm{CH}_{3} \mathrm{C}(\mathrm{O}) \mathrm{OH}$ & $+5^{3}$ & +0.0739 & 0.01478 \\
\hline $\mathrm{HNO}_{3}$ & $+0.25^{3}$ & $\|<0.0001$ & $\|<0.0004$ \\
\hline $\mathrm{C}_{3} \mathrm{H}_{7}(\mathrm{O}) \mathrm{NO}_{2}^{8}$ & $+0.05^{3}$ & $\|<0.0001$ & $\|<0.0002$ \\
\hline ISOOH & $+0.865^{2}$ & 0 & 0 \\
\hline $\mathrm{C}_{3} \mathrm{H}_{7} \mathrm{OOH}$ & $+0.865^{2}$ & $\|<0.002$ & $\|<0.002$ \\
\hline
\end{tabular}

$0.1-4 \mathrm{nmol} / \mathrm{mol}$ in rural and $0.1-1 \mathrm{nmol} / \mathrm{mol}$ in remote areas given by Finlayson-Pitts and Pitts (2000) and from a value of approximately $0.13 \mathrm{nmol} / \mathrm{mol}$ reported by Jacob and Wofsy (1990) for the Brazilian rainforest during the wet season. The sensitivity towards $\mathrm{HNO}_{3}$, organic nitrates from higher alkyl nitrates and from the reaction of $\mathrm{C}_{3} \mathrm{H}_{6}$ with $\mathrm{NO}_{3}$ (ONIT), and i-propyl nitrate was tested with mixing ratios of 0.25 , 0.05 and $0.05 \mathrm{nmol} / \mathrm{mol}$, respectively, derived as upper limits from ABLE measurements and model results by Jacob and Wofsy $(1988,1990)$. A model run with freely calculated $\mathrm{NO}_{\mathrm{z}}$ gave maximum mixing ratios of $125 \mathrm{pmol} / \mathrm{mol}$ $\left(\mathrm{HNO}_{3}\right), 0.1 \mathrm{pmol} / \mathrm{mol}\left(\mathrm{C}_{3} \mathrm{H}_{7} \mathrm{ONO}_{2}\right), 6 \mathrm{pmol} / \mathrm{mol}$ (ONIT), $183 \mathrm{pmol} / \mathrm{mol}$ (NACA) and $285 \mathrm{pmol} / \mathrm{mol}$ (nitrate from isoprene oxidation, ISON), clearly smaller than the values used for the sensitivity test (see below). When calculated freely the levels of the mixing ratios of MEK, hydroxy acetone and methyl glyoxal $\left(\mathrm{CH}_{3} \mathrm{C}(\mathrm{O}) \mathrm{CH}_{2} \mathrm{OH}\right)$ are at about $2 \mathrm{pmol} / \mathrm{mol}, 1.3 \mathrm{nmol} / \mathrm{mol}$ and $0-300 \mathrm{pmol} / \mathrm{mol}$. Sensitivity runs were performed with mixing ratios of $1.8 \mathrm{nmol} / \mathrm{mol}$ and $606 \mathrm{pmol} / \mathrm{mol}$ for MEK and hydroxy acetone (mixing ratios reported for the BL during LBA-CLAIRE in Williams et al.,
$2001 \mathrm{~b}$ ). If the identification of $\mathrm{m} 73$ as MEK proposed in that study is correct, the striking difference between modelled and measured MEK suggests that direct emissions of MEK are much more important than its photochemical production. In the case of methyl glyoxal the chemical lifetime is so short (visible in the diurnal cycle) that the chemistry is approximated by steady state.

The at first glance surprisingly low sensitivity of $\mathrm{CO}$ towards isoprene and $\mathrm{CH}_{3} \mathrm{OOH}$ in the model can be explained by the fixed intermediate ( $\mathrm{HCHO}$ and $\mathrm{MVK}$ ) mixing ratios via which the oxidation of these two species primarily proceeds (see e.g. Stickler et al., 2006). The high sensitivity towards $\mathrm{NO}_{3}$ is caused by a generally higher formation rate of the peroxyacetyl radical by the reaction sequence

$$
\begin{aligned}
& \mathrm{C}_{2} \mathrm{H}_{5} \mathrm{O}_{2}+\mathrm{NO}_{3} \rightarrow \mathrm{CH}_{3} \mathrm{CHO}+\mathrm{HO}_{2}+\mathrm{NO}_{2} \\
& \mathrm{CH}_{3} \mathrm{CHO}+\mathrm{NO}_{3} \stackrel{\mathrm{O}_{2}}{\rightarrow} \mathrm{CH}_{3} \mathrm{C}(\mathrm{O}) \mathrm{OO}+\mathrm{HNO}_{3}
\end{aligned}
$$

The formed radical can further react with $\mathrm{NO}_{3}$, producing $\mathrm{CH}_{3} \mathrm{O}_{2}$ and $\mathrm{CO}_{2}$, thus partly bypassing $\mathrm{CO}$ as intermediate:

$$
\mathrm{CH}_{3} \mathrm{C}(\mathrm{O}) \mathrm{OO}+\mathrm{NO}_{3} \rightarrow \mathrm{CH}_{3} \mathrm{O}_{2}+\mathrm{NO}_{2}+\mathrm{CO}_{2}
$$


At the same time the equilibrium of the reaction

$$
\mathrm{CH}_{3} \mathrm{C}(\mathrm{O}) \mathrm{OO}+\mathrm{NO}_{2} \rightleftharpoons \mathrm{PAN}
$$

is shifted towards the reservoir species peroxyacetyl nitrate due to the fact that the $\mathrm{NO}_{2}$ mixing ratios are much higher in this case compared to the reference run and induced by the reactions

$$
\begin{aligned}
& \mathrm{CH}_{3} \mathrm{O}_{2}+\mathrm{NO}_{3} \rightarrow \mathrm{HCHO}+\mathrm{HO}_{2}+\mathrm{NO}_{2} \\
& \mathrm{C}_{2} \mathrm{H}_{5} \mathrm{O}_{2}+\mathrm{NO}_{3} \rightarrow \mathrm{CH}_{3} \mathrm{CHO}+\mathrm{HO}_{2}+\mathrm{NO}_{2}
\end{aligned}
$$

and Reaction (RB3), further slowing down the CO production. Interestingly, the sensitivity of CO towards NACA and ISON is not negligible, as initially expected. This can be understood considering that Stickler et al. (2006) suggested that, in the upper troposphere, these compounds would accumulate to unrealistically high mixing ratios in a simple steady state box model. Therefore it seemed reasonable in that study to neglect them without consequences for the $\mathrm{HCHO}$ or CO budgets. On the other hand the present study examines boundary layer chemistry in a region strongly affected by precursor emissions of the two species, so that the potential influence of the latter on $\mathrm{CO}$ has to be estimated at least in the context of a sensitivity study. CO shows no sensitivity at all towards ISOOH in the model. This can be understood considering that ISOOH reacts with $\mathrm{OH}$ to form MVK and photolyses to give $\mathrm{MVK}, \mathrm{HCHO}, \mathrm{HO}_{2}$ and $\mathrm{OH}$ as products, all compounds prescribed on the basis of the measurements. Thus changing the partitioning of the organic peroxide in favour of ISOOH leads to a decrease in $\mathrm{CO}$.

Acknowledgements. We thank U. Parchatka for measuring and processing the NO and ozone data as well as for technical support. Thanks further go to T. Klüpfel for supervising the PTR-MS measurements and to S. Bartenbach for part of the GC analysis of isoprene. For the ECMWF trajectories we express our gratitude to the Royal Netherlands Meteorological Institute (KNMI, De Bilt (The Netherlands)). We appreciate the good cooperation with the Suriname Meteorological Service (MDS) and the Anton de Kom University of Suriname (both Paramaribo (Suriname)). Additionally, we wish to thank Enviscope GmbH (Frankfurt (Germany)) for the flight/meteorological data and technical support, and R. Königstedt for the $J\left(\mathrm{NO}_{2}\right)$ measurements as well as technical and engineering support. Finally, we acknowledge the work of the pilots and the technicians of the GFD (Gesellschaft für Flugzieldarstellung, Hohn (Germany)).

Edited by: R. Cohen

\section{References}

Baer, M. and Nester, K.: Parameterization of trace gas dry deposition velocities for a regional mesoscale diffusion model, Ann. Geophys., 10, 912-923, 1992, http://www.ann-geophys.net/10/912/1992/.
Barket, D. J., Grossenbacher, J. W., Hurst, J. M., Shepson, P. B., Olszyna, K., Thornberry, T., Carroll, M. A., Roberts, J., Stroud, C., Bottenheim, J., and Biesenthal, T.: A study of the $\mathrm{NO}_{\mathrm{x}}$ dependence of isoprene oxidation, J. Geophys. Res., 109, D11310, doi:10.1029/2003JD003965, 2004.

Brenninkmeijer, C. A. M., Koeppel, C., Röckmann, T., Scharffe, D. S., Bräunlich, M., and Gros, V.: Absolute measurement of the abundance of atmospheric carbon monoxide, J. Geophys. Res., 106, $10003-10010,2001$.

Carvalho, L. R. F., Vasconcellos, P. C., Mantovani, W., Pool, C. S., and Pisani, S. O.: Measurements of biogenic hydrocarbons and carbonyl compounds emitted by forest trees from temperate warm Atlantic rainforest, Brazil, J. Environ. Monit., 7, 493-499, 2005.

Chang, C.-T., Liu, T.-H., and Jeng, F.-T.: Atmospheric concentrations of the $\mathrm{Cl}$ atom, $\mathrm{ClO}$ radical, and $\mathrm{HO}$ radical in the coastal marine boundary layer, Environ. Res., 94, 67-74, 2004.

Chatfield, R. B., Vastano, J. A., Li, L., Sachse, G. W., and Connors, V. S.: The Great African plume from biomass burning: Generalizations from a three-dimensional study of TRACE A carbon monoxide, J. Geophys. Res., 103, 28 059-28 077, 1998.

Conrad, R. and Seiler, W.: Influence of temperature, moisture, and organic carbon on the flux of $\mathrm{H}_{2}$ and $\mathrm{CO}$ between soil and atmosphere: Field studies in subtropical regions, J. Geophys. Res., 90, 5699-5709, 1985.

de Reus, M., Fischer, H., Sander, R., Gros, V., Kormann, R., Salisbury, G., van Dingenen, R., Williams, J., Zöllner, M., and Lelieveld, J.: Observations and model calculations of trace gas scavenging in a dense Saharan dust plume during MINATROC, Atmos. Chem. Phys., 5, 1787-1803, 2005, http://www.atmos-chem-phys.net/5/1787/2005/.

Dillon, M. B., Lamanna, M. S., Schade, G. W., Goldstein, A. H., and Cohen, R. C.: Chemical evolution of the Sacramento urban plume: Transport and oxidation, J. Geophys. Res., 107(D5), doi: 10.1029/2001JD000969, 2002.

Faloona, I.: Observations of $\mathrm{HO}_{\mathrm{x}}$ and its relationship with $\mathrm{NO}_{\mathrm{x}}$ in the upper troposphere during SONEX, J. Geophys. Res., 105, 3771-3783, 2000.

Fan, J. and Zhang, R.: Atmospheric oxidation mechanism of isoprene, Environ. Chem., 1, 140-149, 2004.

Fehsenfeld, F., Calvert, J., Fall, R., Goldan, P., Guenther, A. B., Hewitt, C. N., Lamb, B., Liu, S., Trainer, M., Westberg, H., and Zimmerman, P.: Emissions of volatile organic compounds from vegetation and the implications for atmospheric chemistry, Global Biogeochem. Cycles, 6, 389-430, 1992.

Finlayson-Pitts, B. J. and Pitts, J. N. (Eds.): Chemistry of the Upper and Lower Atmosphere, Academic Press, London (UK), 2000.

Ganzeveld, L., Klemm, O., Rappenglück, B., and ValverdeCanossa, J.: Evaluation of meteorological parameters over a coniferous forest in a single-column chemistry-climate model, Atmos. Environ., 40, S21-S27, doi:10.1016/j.atmosenv.2006.01. 061, 2006a.

Ganzeveld, L., Valverde-Canossa, J., Moortgat, G. K., and Steinbrecher, R.: Evaluation of peroxide exchanges over a coniferous forest in a single-column chemistry-climate model, Atmos. Environ., 40, S68-S80, doi:10.1016/j.atmosenv.2006.01.062, 2006b.

Ganzeveld, L. N., Lelieveld, J., Dentener, F. J., Krol, M. C., and Roelofs, G.-J.: Atmosphere-biosphere trace gas exchanges simulated with a single-column model, J. Geophys. Res., 107, 4320, 
doi:10.1029/2001JD000684, 2002.

Gao, W., Wesely, M. L., and Doskey, P. V.: Numerical modeling of the turbulent diffusion and chemistry of $\mathrm{NO}_{\mathrm{x}}, \mathrm{O}_{3}$, isoprene, and other reactive trace gases in and above a forest canopy, $\mathrm{J}$. Geophys. Res., 98, 18339-18353, 1993.

Hall, B. D. and Claiborn, C. S.: Measurements of the dry deposition of peroxides to a Canadian boreal forest, J. Geophys. Res., 102, 29343-29353, 1997.

Hasson, A. S., Tyndall, G. S., and Orlando, J. J.: A product yield study of the reaction of $\mathrm{HO}_{2}$ radicals with ethyl peroxy $\left(\mathrm{C}_{2} \mathrm{H}_{5} \mathrm{O}_{2}\right)$, acetyl peroxy $\left(\mathrm{CH}_{3} \mathrm{C}(\mathrm{O}) \mathrm{O}_{2}\right)$, and acetonyl peroxy $\left(\mathrm{CH}_{3} \mathrm{C}(\mathrm{O}) \mathrm{CH}_{2} \mathrm{O}_{2}\right)$ radicals, J. Phys. Chem. A, 108, 5979-5989, 2004.

Heikes, B., Lee, M., Jacob, D., Talbot, R., Bradshaw, J., Singh, H., Blake, D., Anderson, B., Fuelberg, H., and Thompson, A. M.: Ozone, hydroperoxides, oxides of nitrogen, and hydrocarbon budgets in the marine boundary layer over the South Atlantic, J. Geophys. Res., 101, 24 221-24 234, 1996.

Helas, G., Bingemer, H., and Andreae, M. O.: Organic-acids over equatorial Africa - Results from DECAFE-88, J. Geophys. Res., 97, 6187-6193, 1992.

Holton, J. R. (Ed.): An Introduction to Dynamic Meteorology, vol. 48 of International Geophysics Series, Academic Press, London (UK), 1992.

Jacob, D. J. and Wofsy, S. C.: Photochemistry of biogenic emissions over the Amazon forest, J. Geophys. Res., 93, 1477-1486, 1988.

Jacob, D. J. and Wofsy, S. C.: Budgets of reactive nitrogen, hydrocarbons, and ozone over the Amazon-forest during the wet season, J. Geophys. Res., 95, 16 737-16 754, 1990.

Junkermann, W. and Stockwell, W. R.: On the budget of photooxidants in the marine boundary layer of the tropical South Atlantic, J. Geophys. Res., 104, 8039-8046, 1999.

Kesselmeier, J. and Staudt, M.: Biogenic volatile organic compounds (VOC): An overview on emission, physiology and ecology, J. Atmos. Chem., 33, 23-88, 1999.

Kirchhoff, V. W. J. H. and Marinho, E. V. A.: Surface carbon monoxide measurements in Amazonia, J. Geophys. Res., 95, 16933-16943, 1990.

Krinke, S. M. W.: Experimentelle Bestimmung der Depositionsgeschwindigkeit von Formaldehyd und Ozon über einem Laubwaldbestand, $\mathrm{PhD}$ thesis, University Stuttgart, Faculty of Chemistry, 1999.

Lazrus, A. L., Kok, G. L., Gitlin, S. N., and Lind, J. A.: Automated fluorometric method for hydrogen peroxide in atmospheric precipitation, Anal. Chem., 57, 917-922, 1985.

Lazrus, A. L., Kok, G. L., Lind, J. A., Gitlin, S. N., Heikes, B. G., and Shetter, R. E.: Automated fluorometric method for hydrogen peroxide in air, Anal. Chem., 58, 594-597, 1986.

Loveland, T. R., Reed, B. C., Brown, J. F., Ohlen, D. O., Zhu, Z., Yang, L., and Merchant, J. W.: Development of a global land cover characteristics database and IGBP DISCover from $1 \mathrm{~km}$ AVHRR data, Int. J. Remote Sensing, 21, 1303-1330, 2000.

Lowe, D. C., Allan, W., Manning, M. R., Bromley, T., Brailsford, G., Ferretti, D., Gomez, A., Knobben, R., Martin, R., Mei, Z., Moss, R., Koshy, K., and Maata, M.: Shipboard determinations of the distribution of ${ }^{13} \mathrm{C}$ in atmospheric methane in the Pacific, J. Geophys. Res., 104, 26 125-26 135, 1999.

Madronich, S. and Flocke, S.: The role of solar radiation in atmospheric chemistry, in: Handbook of Environmental Chemistry, edited by: Boule, P., pp. 1-26, Springer, Heidelberg, 1998.

Matthews, J., Sinha, A., and Francisco, J. S.: The importance of weak absorption features in promoting tropospheric radical production, Proc. Nat. Acad. Sci., 102, 7449-7452, 2005.

McKeen, S. A., Gierczak, T., Burkholder, J. R., Wennberg, P. O., Hanisco, T. F., Keim, E. R., Gao, R.-S., Liu, S. C., Ravishankara, A. R., and Fahey, D. W.: The photochemistry of acetone in the upper troposphere: A source of odd-hydrogen radicals, Geophys. Res. Lett., 24, 3177-3180, 1997.

Padhy, P. K. and Varshney, C. K.: Isoprene emission from tropical tree species, Environ. Pollut., 135, 101-109, 2005.

Paulson, S. E. and Seinfeld, J. H.: Development and evaluation of a photooxidation mechanism for isoprene, J. Geophys. Res., 97, 20 703-20 715, 1992.

Peters, W., Krol, M. C., Fortuin, J. P. F., Kelder, H. M., Thompson, A. M., Becker, C. R., Lelieveld, J., and Crutzen, P. J.: Tropospheric ozone over a tropical Atlantic station in the Northern Hemisphere: Paramaribo, Surinam $\left(6^{\circ} \mathrm{N}, 55^{\circ} \mathrm{W}\right)$, Tellus, 56B, 21-34, 2004.

Platt, U., Allan, W., and Lowe, D.: Hemispheric average $\mathrm{Cl}$ atom concentration from ${ }^{13} \mathrm{C} /{ }^{12} \mathrm{C}$ ratios in atmospheric methane, Atmos. Chem. Phys., 4, 2393-2399, 2004,

http://www.atmos-chem-phys.net/4/2393/2004/.

Pöschl, U., von Kuhlmann, R., Poisson, N., and Crutzen, P. J.: Development and intercomparison of condensed isoprene oxidation mechanisms for global atmospheric modeling, J. Atmos. Chem., 37, 29-52, 2000.

Price, H. U., Jaffe, D. A., Cooper, O. R., and Doskey, P. V.: Photochemistry, ozone production, and dilution during long-range transport episodes from Eurasia to the northwest United States, J. Geophys. Res., 109, D23S13, doi:10.1029/2003JD004400, 2004.

Quesada, J., Grossmann, D., Fernández, E., Romero, J., Sanhueza, E., Moortgat, G., and Crutzen, P. J.: Ground based gas phase measurements in Surinam during the LBA-CLAIRE 98 experiment, J. Atmos. Chem., 39, 15-36, 2001.

Roeckner, E., Arpe, K., Bengtsson, L., Christoph, M., Claussen, M., Dümenil, L., Esch, M., Giorgetta, M., Schlese, U., and Schulzweida, U.: The atmospheric general circulation model ECHAM-4: Model description and simulation of present-day climate, Tech. rep., Max-Planck-Institut für Meteorologie, Hamburg (Germany), 1996.

Roeckner, E., Bengtsson, L., Feichter, J., Lelieveld, J., and Rodhe, H.: Transient climate change simulations with a coupled atmosphere-ocean GCM including the tropospheric sulfur cycle, J. Climate, 12, 3004-3032, 1999.

Rottenberger, S., Kuhn, U., Wolf, A., Schebeske, G., Oliva, S. T., Tavares, T. M., and Kesselmeier, J.: Exchange of short-chain aldehydes between Amazonian vegetation and the atmosphere, Ecol. Appl., 14(4) Supplement, S247-S262, 2004.

Sander, R., Kerkweg, A., Jöckel, P., and Lelieveld, J.: Technical Note: The new comprehensive atmospheric chemistry module MECCA, Atmos. Chem. Phys., 5, 445-450, 2005, http://www.atmos-chem-phys.net/5/445/2005/.

Sanhueza, E., Donoso, L., Scharffe, D., and Crutzen, P. J.: Carbon monoxide fluxes from natural, managed, or cultivated savannah grassland, J. Geophys. Res., 99, 16421-16427, 1994.

Scharffe, D., Hao, W. M., Donoso, L., Crutzen, P. J., and Sanhueza, E.: Soil fluxes and atmospheric concentration of $\mathrm{CO}$ and $\mathrm{CH}_{4}$ in 
the northern part of the Guayana Shield, Venezuela, J. Geophys. Res., 95, 22 475-22 480, 1990.

Schmidt, U.: Molecular hydrogen in the atmosphere, Tellus, 26, 78-90, 1978.

Schmidt, U.: The latitudinal and vertical distribution of molecular hydrogen in the troposphere, J. Geophys. Res., 83, 941-946, 1978.

Schönwiese, C.-D. (Ed.): Praktische Statistik für Meteorologen und Geowissenschaftler, Gebrüder Bornträger, Berlin (Germany), 1992.

Seinfeld, J. H. and Pandis, S. N. (Eds.): Atmospheric Chemistry and Physics, Wiley, New York, 1998.

Sillman, S., He, D. Y., Pippin, M. R., Daum, P. H., Imre, D. G., Kleinman, L. I., Lee, J. H., and Weinstein-Lloyd, J.: Model correlations for ozone, reactive nitrogen, and peroxides fro Nashville in comparison with measurements: Implications for $\mathrm{O}_{3}-\mathrm{NO}_{\mathrm{x}}$-hydrocarbon chemistry, J. Geophys. Res., 103, 22 629$22644,1998$.

Singh, H. B., Gregory, G. L., Anderson, B., Browell, E., Sachse, G. W., Davis, D. D., Crawford, J., Bradshaw, J. D., Talbot, R., Blake, D. R., Thornton, D., Newell, R., and Merrill, J.: Low ozone in the marine boundary layer of the tropical Pacific Ocean: Photochemical loss, chlorine atoms, and entrainment, J. Geophys. Res., 101, 1907-1917, 1996.

Stevens, P. S.: $\mathrm{HO}_{2} / \mathrm{OH}$ and $\mathrm{RO}_{2} / \mathrm{HO}_{2}$ rates during the Tropospheric $\mathrm{OH}$ Photochemistry Experiment: Measurement and theory, J. Geophys. Res., 102, 6379-6391, 1997.

Stickler, A.: HCHO, $\mathrm{H}_{2} \mathrm{O}_{2}$ und $\mathrm{CH}_{3} \mathrm{OOH}$ in der Troposphäre, $\mathrm{PhD}$ thesis, Johannes Gutenberg University Mainz, Faculty of Physics, http://ubm.opus.hbz-nrw.de/volltexte/2006/ 1130/pdf/diss.pdf, 2006.

Stickler, A., Fischer, H., Williams, J., de Reus, M., Sander, R., Lawrence, M. G., Crowley, J. N., and Lelieveld, J.: Influence of summertime deep convection on formaldehyde in the middle and upper troposphere over Europe, J. Geophys. Res., 111, D14308, doi:10.1029/2005JD007001, 2006.

Sumner, A. L., Shepson, P. B., Couch, T. L., Thornberry, T., Carroll, M. A., Sillman, S., Pippin, M., Bertman, S., Tan, D., Faloona, I., Brune, W., Young, V., Cooper, O., Moody, J., and Stockwell, W.: A study of formaldehyde chemistry above a forest canopy, J. Geophys. Res., 106(D20), 24 387-24 405, 2001.

Tao, Z. and Jain, A. K.: Modeling of global biogenic emissions for key indirect greenhouse gases and their response to atmospheric $\mathrm{CO}_{2}$ increases and changes in land cover and climate, J. Geophys. Res., 110, D21309, doi:10.1029/2005JD005874, 2005.
Tarr, M. A., Miller, W. L., and Zepp, R. G.: Direct carbon monoxide photoproduction from plant matter, J. Geophys. Res., 100, 11 403-11 413, 1995.

Thornton, J. A., Wooldridge, P. J., Cohen, R. C., Martinez, M., Harder, H., Brune, W. H., Williams, E. J., Roberts, J. M., Fehsenfeld, F. C., Hall, S. R., Shetter, R. E., Wert, B. P., and Fried, A.: Ozone production rates as a function of $\mathrm{NO}_{\mathrm{x}}$ abundances and $\mathrm{HO}_{\mathrm{x}}$ production rates in the Nashville urban plume, J. Geophys. Res., 107, 4146, doi:10.1029/2001JD000932, 2002.

Valverde-Canossa, J., Ganzeveld, L., Rappenglück, B., Steinbrecher, R., Klemm, O., Schuster, G., and Moortgat, G. K.: First measurements of $\mathrm{H}_{2} \mathrm{O}_{2}$ and organic peroxides surface fluxes by the relaxed eddy-accumulation technique, Atmos. Environ., 40, S55-S67, doi:10.1016/j.atmosenv.2006.03.038, 2006.

von Glasow, R., Sander, R., Bott, A., and Crutzen, P. J.: Modeling halogen chemistry in the marine boundary layer 1 . Cloud-free MBL, J. Geophys. Res., 107, doi:10.1029/2001JD000942, 2002.

von Kuhlmann, R., Lawrence, M. G., Pöschl, U., and Crutzen, P. J.: Sensitivities in global scale modeling of isoprene, Atmos. Chem. Phys., 4, 1-17, 2004,

http://www.atmos-chem-phys.net/4/1/2004/.

Walcek, C. J.: A theoretical estimate of $\mathrm{O}_{3}$ and $\mathrm{H}_{2} \mathrm{O}_{2}$ dry deposition over the northeast United-States, Atmos. Environ., 21, 2649-2659, 1987.

Williams, J., Fischer, H., Hoor, P., Pöschl, U., Crutzen, P. J., Andreae, M. O., and Lelieveld, J.: The influence of the tropical rainforest on atmospheric $\mathrm{CO}$ and $\mathrm{CO}_{2}$ as measured by aircraft over Surinam, South America, Chemosph.-Global Change Science, 3, 157-170, 2001a.

Williams, J., Pöschl, U., Crutzen, P. J., Hansel, A., Holzinger, R., Warneke, C., Lindinger, W., and Lelieveld, J.: An atmospheric chemistry interpretation of mass scans obtained from a Proton Transfer Mass Spectrometer flown over the tropical rainforest of Surinam, J. Atmos. Chem., 38, 133-166, 2001 b.

Wingenter, O. W., Kubo, M. K., Blake, N. J., Smith, T. W., Blake, D. R., and Rowland, F. S.: Hydrocarbon and halocarbon measurements as photochemical and dynamical indicators of atmospheric hydroxyl, atomic chlorine, and vertical mixing obtained during Lagrangian flights, J. Geophys. Res., 101, 4331-4340, 1996.

Zimmerman, P. R., Greenberg, J. P., and Westberg, C. E.: Measurements of atmospheric hydrocarbons and biogenic emission fluxes in the Amazon boundary layer, J. Geophys. Res., 93, 1407-1416, 1988. 